\title{
Acetylcholine Release in Prefrontal Cortex Promotes Gamma Oscillations and Theta-Gamma Coupling during Cue Detection
}

\author{
William M. Howe, ${ }^{1,2,3 *} \oplus^{-H o w a r d ~ J . ~ G r i t t o n, ~}{ }^{1,2 *}{ }^{-}$Nicholas A. Lusk, ${ }^{1}{ }^{\oplus E}$ Erik A. Roberts, ${ }^{2}$ Vaughn L. Hetrick, ${ }^{1}$ \\ Joshua D. Berke, ${ }^{1,4}$ and $\odot$ Martin Sarter ${ }^{1}$ \\ ${ }^{1}$ Department of Psychology and Neuroscience Program, University of Michigan, Ann Arbor, Michigan 48109, ${ }^{2}$ Department of Biomedical Engineering, \\ Boston University, Boston, Massachusetts 02215, ${ }^{3} \mathrm{Icahn}$ School of Medicine at Mt. Sinai, New York, New York 10029, and ${ }^{4}$ Department of Neurology and \\ Center for Integrative Neuroscience, University of California, San Francisco, San Francisco, California 94143
}

The capacity for using external cues to guide behavior ("cue detection") constitutes an essential aspect of attention and goal-directed behavior. The cortical cholinergic input system, via phasic increases in prefrontal acetylcholine release, plays an essential role in attention by mediating such cue detection. However, the relationship between cholinergic signaling during cue detection and neural activity dynamics in prefrontal networks remains unclear. Here we combined subsecond measures of cholinergic signaling, neurophysiological recordings, and cholinergic receptor blockade to delineate the cholinergic contributions to prefrontal oscillations during cue detection in rats. We first confirmed that detected cues evoke phasic acetylcholine release. These cholinergic signals were coincident with increased neuronal synchrony across several frequency bands and the emergence of theta-gamma coupling. Muscarinic and nicotinic cholinergic receptors both contributed specifically to gamma synchrony evoked by detected cues, but the effects of blocking the two receptor subtypes were dissociable. Blocking nicotinic receptors primarily attenuated high-gamma oscillations occurring during the earliest phases of the cue detection process, while muscarinic (M1) receptor activity was preferentially involved in the transition from high to low gamma power that followed and corresponded to the mobilization of networks involved in cue-guided decision making. Detected cues also promoted coupling between gamma and theta oscillations, and both nicotinic and muscarinic receptor activity contributed to this process. These results indicate that acetylcholine release coordinates neural oscillations during the process of cue detection.

Key words: acetylcholine; oscillations; prefrontal cortex

Significance Statement

The capacity of learned cues to direct attention and guide responding ("cue detection") is a key component of goal-directed behavior. Rhythmic neural activity and increases in acetylcholine release in the prefrontal cortex contribute to this process; however, the relationship between these neuronal mechanisms is not well understood. Using a combination of in vivo neurochemistry, neurophysiology, and pharmacological methods, we demonstrate that cue-evoked acetylcholine release, through distinct actions at both nicotinic and muscarinic receptors, triggers a procession of neural oscillations that map onto the multiple stages of cue detection. Our data offer new insights into cholinergic function by revealing the temporally orchestrated changes in prefrontal network synchrony modulated by acetylcholine release during cue detection.

\section{Introduction}

A diverse set of neural processes serves to select predictive cues from competing sensory inputs and allows them to modify be-

Received Aug. 30, 2016; revised Feb. 3, 2017; accepted Feb. 10, 2017.

Author contributions: W.M.H., H.J.G., and M.S. designed research; W.M.H., H.J.G., N.L., and V.L.H. performed research; W.M.H., H.J.G., and E.A.R. analyzed data; W.M.H., H.J.G., E.A.R., J.D.B., and M.S. wrote the paper.

This work was supported in part by Public Health Service Grants R01MH086530 and P50NS091856 and internal funds (M.S.). The authors thank Cassandra Avila and Dr. Ajeesh Koshy Cherian for technical assistance.

*W.M.H. and H.J.G. contributed equally to this work.

The authors declare no competing financial interests. havior, a multistage process collectively referred to as cue detection (Posner et al., 1980). Task-relevant stimuli can synchronize activity between ensembles of cells (Engel et al., 2001; Fries et al., 2001; Buschman and Miller, 2007; Gregoriou et al., 2009). Likewise, the presence of coordinated neural activity and spike-field

Correspondence should be addressed to either of the following: W. M. Howe, 1 Gustave Levy Place, New York, NY 10129. E-mail: wmhowe@gmail.com; or M. Sarter, Department of Psychology, University of Michigan, 4030 East Hall, Ann Arbor, Ml 48109, E-mail: msarter@umich.edu.

DOI:10.1523/JNEUROSCI.2737-16.2017

Copyright $\odot 2017$ the authors $\quad 0270-6474 / 17 / 373215-16 \$ 15.00 / 0$ 
coherence at gamma frequencies $(\sim 30-100 \mathrm{~Hz})$ has been observed during states of heightened attention or attentional selection (Fries et al., 2001; Bichot et al., 2005; Womelsdorf and Fries, 2006, 2007). Thus, high-frequency oscillations observed during performance of attention tasks may coordinate activity in neural networks to support cue detection.

In addition to high-frequency activity, lower-frequency oscillations, such as those in the theta $(\sim 5-12 \mathrm{~Hz})$ and beta $(\sim 12-30$ $\mathrm{Hz})$ frequencies, are evoked by stimuli that guide response selection (Bland and Oddie, 2001; Raghavachari et al., 2001; Caplan et al., 2003; Saleh et al., 2010; Cruikshank et al., 2012; Leventhal et al., 2012). For example, prefrontal theta oscillations are elevated by instructive spatial cues in humans (Kaplan et al., 2014) and rodents (Hyman et al., 2005; Jones and Wilson, 2005). In some instances, low- and high-frequency rhythms become linked through phase-amplitude coupling, and this cross-phase coordination can be a strong predictor of response accuracy or learning rate (Tort et al., 2008, 2009; Canolty and Knight, 2010). Such coupling may be particularly important when decision and response processes coincide with, or are informed by, attentioncapturing sensory cues to facilitate learning or memory processes (Tort et al., 2008; Cohen et al., 2009; Kaplan et al., 2014).

The essential neural signaling events that underlie stimulusevoked coordination of cortical networks remain to be determined, but likely involve activation of the cortical cholinergic input system. The detection of cues in attentional contexts depends on cholinergic activity in the cortex (McGaughy et al., 1996). Furthermore, transient, or phasic, increases in acetylcholine $(\mathrm{ACh})$ release in prefrontal cortex (PFC) mediate, and are necessary for, cue detection (Kozak et al., 2006; Parikh et al., 2007; St Peters et al., 2011; Howe et al., 2013; Gritton et al., 2016). Cortical pyramidal cells, GABAergic interneurons, and the terminals of thalamic afferent projections all express cholinergic receptors (Disney and Aoki, 2008; Parikh et al., 2008; Parikh et al., 2010), giving the cortical cholinergic system the capacity to shape activity that emerges from interactions between cortical neurons during attentional performance. This idea is supported by evidence indicating that stimulus-evoked spike coherence is sensitive to manipulations of cholinergic activity (Rodriguez et al., 2004; Herrero et al., 2008), and that large-scale synchronous neural activity induced by attended stimuli requires the activation of muscarinic receptors (Rodriguez et al., 2004). Furthermore, it has been shown that theta oscillations accompany behaviorally relevant stimuli, and that neurons of the nucleus basalis support the generation of both theta and gamma oscillations in the rodent PFC (Lin et al., 2006).

Here, we explore the relationships between phasic cholinergic signaling and cue-evoked oscillations in the PFC. Previous experiments demonstrated that in rats performing a pavlovian cuedapproach task, cues that are detected evoke transient increases in ACh release in the PFC (Parikh et al., 2007). We first replicated this prior finding using amperometry and choline-sensitive microelectrodes in task-performing rats. Next, we recorded local field potentials (LFPs) via those same electrodes while pharmacologically blocking either muscarinic (mAChRs) or nicotinic acetylcholine receptors (nAChRs) at the recording site. We found that cholinergic signaling contributes to multiple and temporally distinct components of prefrontal oscillations during cue detection via activation of different receptor subtypes. Our combined data support a major role for cholinergic signaling in the coordination of prefrontal neural activity during cue detection.

\section{Materials and Methods}

Subjects. Adult male Fisher-Brown Norway rats (Harlan) weighing 200$250 \mathrm{~g}$ at the beginning of the experiments were used in the present experiments $(N=9)$. All procedures were conducted in adherence with protocols approved by the Institutional Animal care and Use Committee of the University of Michigan. Animals were trained $5 \mathrm{~d}$ per week. Water was available only as a reward and for $30 \mathrm{~min}$ after the completion of training. Food was available ad libitum. All training and testing took place during the light cycle between 8:00 A.M. and 5:00 P.M.

Behavioral training. Our initial experiments leading to the discovery of phasic ACh release and its relationship to cue detection used a cued appetitive response task (Parikh et al., 2007). Subsequent studies have since applied more complex tasks, requiring not just the detection of cues but also responding in noncue trials, and the same amperometric technique to demonstrate the specific role of phasic ACh release during cue detection (Howe et al., 2013). The main goal of the present experiments was to determine how cue-driven, phasic ACh release events orchestrate local neuronal activity. To this end, we used the cued appetitive response task used in our original experiments because this task offers a clear separation between the cue-evoked phasic ACh release event and the reward delivery and retrieval period. The relative simplicity of this task also allowed for better control of potential electrical or mechanical artifacts that are prevalent in complex behavioral paradigms that use motorized response manipulanda. Briefly, in the cued appetitive response task (Fig. $1 \mathrm{~A}$ ), a visual cue ( $1 \mathrm{~s}$ illumination of a ceiling mounted low-intensity light) predicted the later availability of reward $(0.066 \%$ saccharin sweetened water) at one of two randomly selected ports on any given trial. Test sessions consisted of 30 trials, separated by an intertrial interval (ITI) of $90 \pm 30$ s (Fig. 1B). Trials were scored as "hits" or "detections" if cue presentation triggered an interruption of ongoing behavior (typically grooming) and initiated port approach. Responses were "misses" if animals continued self-directed behavior until the sound of reward presentation. Missed cues were occasionally associated with a brief orienting response, but not followed by a reward port approach, highlighting the difference between orienting and detection (Posner et al., 1980). Sweetened water was delivered to the reward port by a liquid dipper arm (Med Associates) $6 \pm 2 \mathrm{~s}$ after cue presentation, regardless of the animals' response to the cue. The reward remained available in the port for $30 \mathrm{~s}$, after which time the dipper arm was retracted and triggered the ITI. Reward was typically consumed in the first several seconds of licking on both hit and miss trials. Trials in which animals did not retrieve reward were scored as omissions and not included in the final analyses (1.5\% of total trials).

Electrode implantation. After reaching performance criterion in the behavioral task ( $>60 \%$ detected cues for 3 consecutive days), a microelectrode/microinfusion assembly was implanted into layer $3 / 5$ of the prelimbic cortex (Fig. 2A; AP, $+3.0 \mathrm{~mm}$; ML, $-0.7 \mathrm{~mm}$; DV , $-3.5 \mathrm{~mm}$ ). The electrodes consisted of four platinum recording sites arranged in side-by-side pairs $(15 \times 333 \mu \mathrm{m}, 30 \mu \mathrm{m}$ horizontally between electrodes in a pair and $100 \mu \mathrm{m}$ vertically between pairs) along a ceramic shank. Each electrode array was equipped with an infusion cannula, positioned such that the infusion stylet used to locally apply compounds was situated in between the two pairs of platinum electrodes, 75-100 $\mu \mathrm{m}$ from the recording surface. The electrode/cannula assembly was held in position by sculpting putty and dental wax for implantation and secured in place by embedding the entire assembly in dental cement anchored by skull screws (Fig. $2 B$ ). An $\mathrm{Ag} / \mathrm{AgCl}$ reference electrode was implanted at a remote location in the opposite hemisphere, and a stainless steel ground screw was implanted $1 \mathrm{~mm}$ behind lambda. Animals were allowed to recover for $48 \mathrm{~h}$ and then habituated to performing the task while tethered.

Choline electrochemistry. To confirm the presence of cholinergic transients during cue detection, we recorded changes in cholinergic activity with fixed potential amperometry before the electrophysiology experiments in a subset of animals. The same platinum electrodes used for electrochemistry were used for electrophysiology (Fig. 2C). Details concerning the preparation and calibration of these electrodes for electrochemistry in task-performing animals have been described previously 
Detected trial
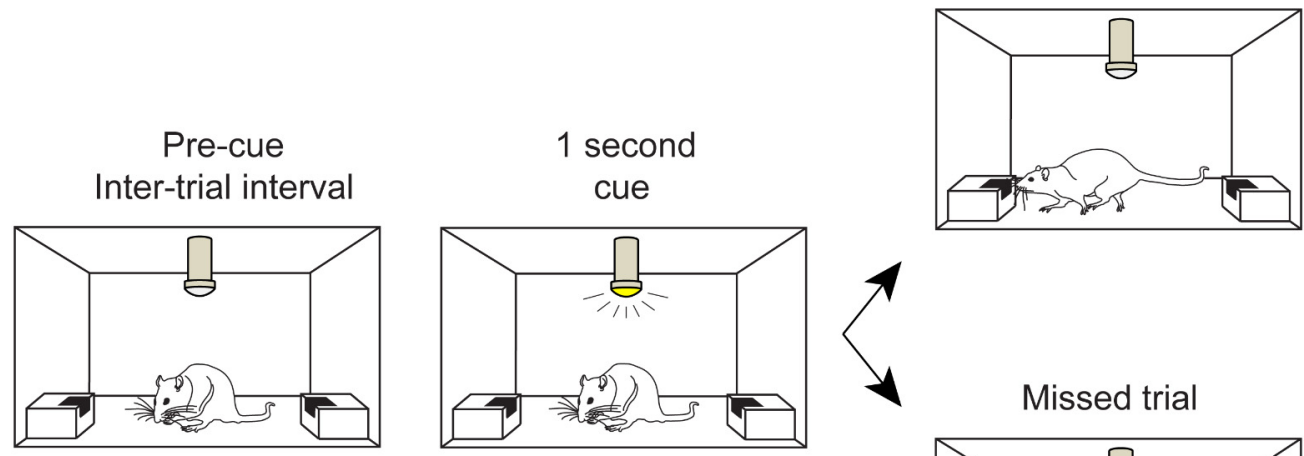

Missed trial

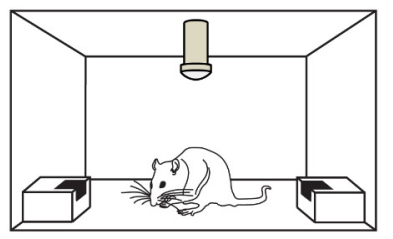

B

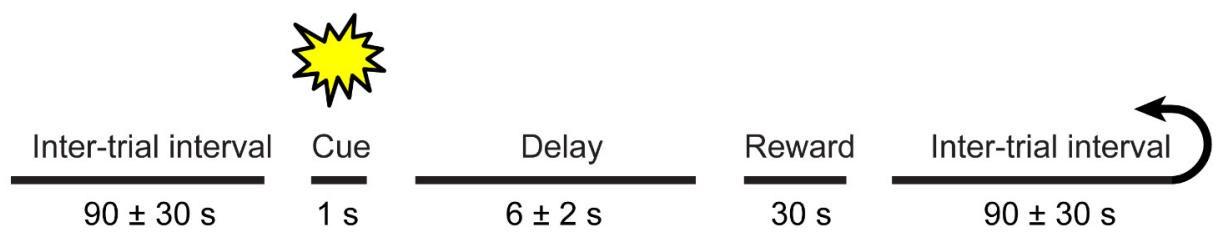

Figure 1. Task description. $\boldsymbol{A}, \boldsymbol{B}$, Animals were trained to perform a cued appetitive response task. A 1 s sillumination of a centrally located, overhead cue light (conditioned stimulus) predicted the later availability of reward ( $6 \pm 2$ s after cue). Reward was available for $30 \mathrm{~s}$, but rewards were typically consumed within the first 1-2 s of availability. Animals were given 30 cue-reward pairings in a session, with trials separated by $90 \pm 30 \mathrm{~s}$.

(Parikh et al., 2007; Howe et al., 2013). Briefly, choline oxidase was immobilized on one pair of electrodes in a BSA/glutaraldehyde protein matrix, while the other pair of recording sites was coated with the protein matrix alone ("sentinel"). Both pairs of recording sites were coated with Nafion to block interferents from being oxidized on the platinum surface (see below for a discussion concerning the selectivity of the electrochemical signal). Electrodes were calibrated to determine their sensitivity to choline as well as their selectivity for choline over ascorbic acid and before implantation. Electrodes were additionally tested for response to dopamine across channels during calibration to allow for dopamine signal normalization (described in Data analysis). The electrodes used in the present experiments were characterized by an average sensitivity of $7.53 \pm 0.31 \mathrm{pA} / \mu \mathrm{M}$ of choline, a selectivity over ascorbic acid (choline: AA) of $80.26 \pm 19.71$, and a highly linear response to ascending concentrations of choline $(20-80 \mu \mathrm{m} ; \mathrm{R}>0.99)$. The choline biosensors used here allow for the detection of subsecond changes in extracellular choline concentrations, and this temporal precision has importantly been demonstrated in vivo. For example, optogenetic stimulation of ChR2expressing cholinergic neurons evokes choline currents in the PFC that peak between $400-500 \mathrm{~ms}$ following laser stimulation onset, and significant increases in current occur within 100-200 ms (Gritton et al., 2016). Additional data, including currents evoked by choline infusions into the vicinity of biosensors located in brain tissue (Parikh and Sarter, 2006), are consistent with the capacity of choline biosensors to reveal changes in acetylcholine on a subsecond timescale.

Behavioral test sessions commenced on the third to fifth day after surgery by placing the animal in the recording chamber and connected them to a FAST-16 potentiostat/data recording system by a shielded cable and a low impedance commutator. Amperometric recordings were acquired at a rate of $2 \mathrm{~Hz}$ and made by applying a fixed potential of $0.7 \mathrm{~V}$ against an $\mathrm{Ag} / \mathrm{AgCl}$ reference electrode. After $\sim 2 \mathrm{~h}$ of baseline recording, the behavioral session was started.

Behavioral testing, pharmacology, and recordings of neural activity. Electrophysiological recordings were conducted in a custom-designed wooden operant chamber completely shielded by copper wire mesh and equipped with two reward ports constructed of fiberboard used for electrical insulation. The entire assembly was connected to an electrical ground. LFP recordings were made using custom amplifiers (Boston University Electronics Design Facility) and LabView (National Instruments) software. Signals were bandpass filtered at $0.1-300 \mathrm{~Hz}$ and amplified $(5000 \times)$, before being digitized with a sampling frequency of $1500 \mathrm{~Hz}$. Testing began after animals had reestablished a stable baseline of performance ( $>3 \mathrm{~d}$ of $>60 \%$ hits). During the test session (Fig. 2D), the first 10 trials (block 1; $\sim 20 \mathrm{~min}$ ) served as a preinfusion baseline. Over the next 10 trials (block 2), the M1 mAChR selective (Noronha-Blob et al., 1988; Galvan et al., 1989) antagonist telenzepine ( $n=9 ; 50 \mathrm{nmol})$, the nicotinic receptor antagonist mecamylamine $(n=8 ; 2 \mathrm{nmol})$, or artificial CSF (ACSF; $n=7$ ) was slowly infused into the recording region at a rate of 50 $\mathrm{nl} / \mathrm{min}$ (total volume, $1 \mu \mathrm{l}$; block 2; 10 trials) while the animal continued to perform. Infusions were delivered slowly as opposed to a single bolus to avoid damaging the surrounding tissue and potentially confounding drug effects with artifacts of the infusion itself. Doses for the two antagonists were selected based on previous literature and pilot experiments aimed at identifying concentrations that reliably affected the LFP (Herremans et al., 1996; Nelson et al., 2005; Newman and Mair, 2007). Animals performed the final 10 trials (block 3 ) following the conclusion of the infusion. The order of drug administration was randomized between animals. Two animals were removed from study due to health concerns and did not complete all infusion conditions.

Data analysis. Behavioral data were analyzed with respect to the number of hits (number of detected cues per total number of trials minus omissions). For the analysis of electrochemical data, current recordings from each recording electrode were converted to concentration values using the sensitivity to choline (picoamperes per micromolar) determined in calibration, normalized by response to dopamine, and then filtered of nonspecific current fluctuations by subtracting data recorded from a sentinel site. While the exclusion barrier used in the current experiments (Nafion, above) provides superior selectivity over ascorbic acid, it does not prevent cationic analytes like dopamine from reaching the electrode surface. Normalizing currents recorded at each site by the 
A

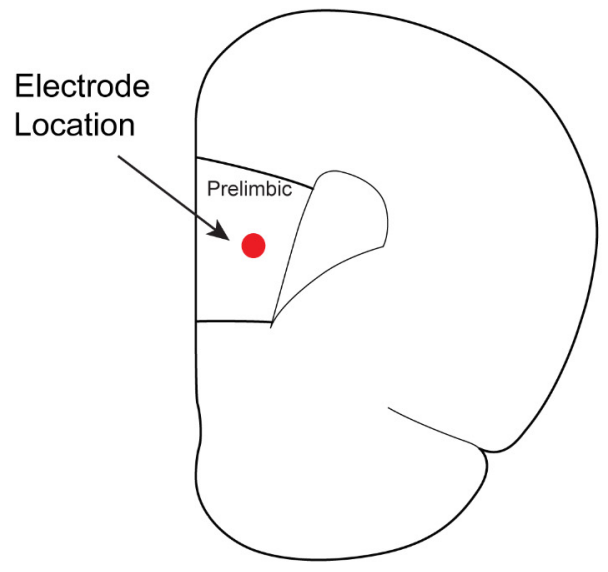

C

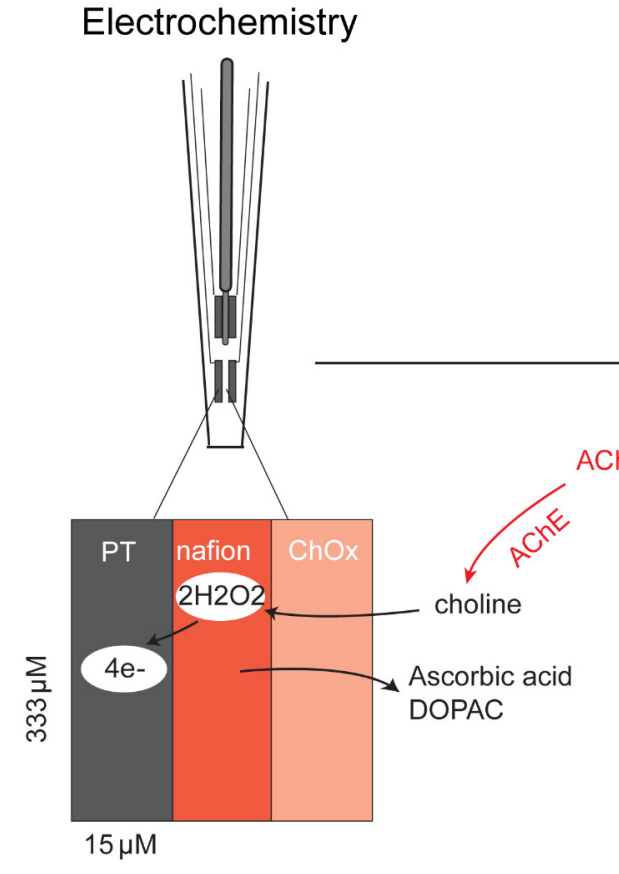

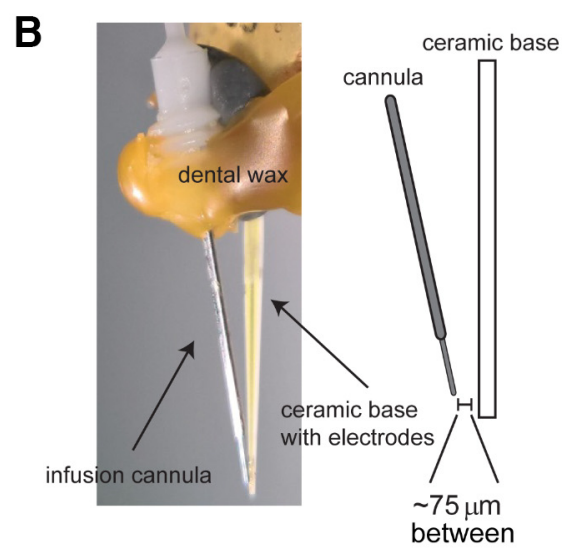

Local Field Potential (LFP)

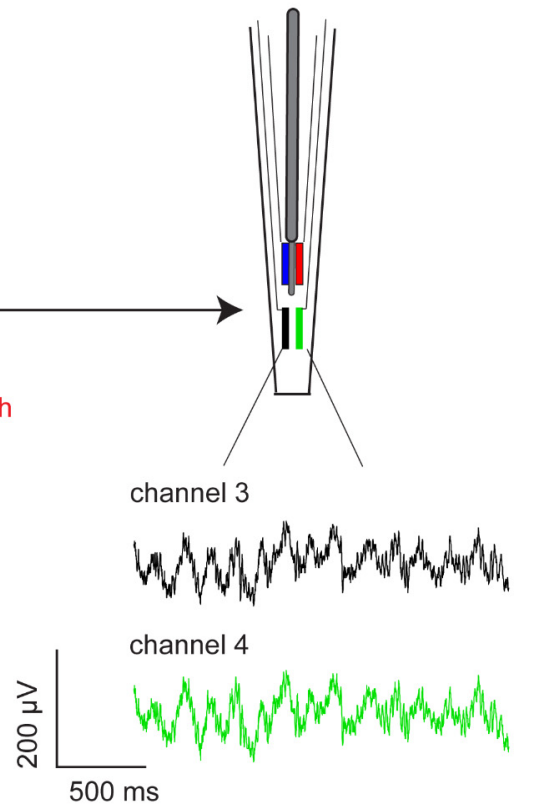

D

\section{Recording Session ( 60 min)}

\begin{tabular}{|c|c|c|}
\hline 10 Trials & 10 Trials & 10 Trials \\
\hline Baseline & Infusion & Post-Infusion \\
\hline
\end{tabular}

Figure 2. Measurement scheme and experimental design. $\boldsymbol{A}$, Platinum (PT) microelectrode arrays were implanted into the prelimbic subregion of right prefrontal cortex. $\boldsymbol{B}$, Local microinfusions were delivered via a cannula connected to the microelectrode array, centered between the four platinum recording sites $\sim 75 \mu \mathrm{m}$ from the recording surface. C, Left, For electrochemical recordings, platinum sites were coated with Nafion to control for the contribution of interferents to current signals. Changes in ACh release were measured by converting choline produced by the hydrolysis of newly released ACh to current on the electrode surface. Right, The same electrodes were used to monitor changes in the local field potential in separate sessions. The green and black traces below are representative local field potentials recorded from two electrodes on the same array. $\boldsymbol{D}$, On drug test days, animals performed 10 baseline trials, followed by 10 trials during which drug (telenzepine, mecamylamine) or vehicle (ACSF) was infused ( $50 \mathrm{nl} / \mathrm{min}$ over $20 \mathrm{~min}$ ) into the recording area while animals continued to perform the task. During the final 10 trials, no infusion occurred.

response to dopamine determined as part of the in vitro calibration is thus used as a means of accounting for the possible contribution of dopamine to currents recorded in vivo. Importantly, confirmed previously that currents measured with this technique and using the same exclusion barrier, in animals performing the same task, depend on the presence of cholinergic terminals (Parikh et al., 2007) and the hydrolysis of newly released ACh by endogenous acetylcholinesterase (Parikh et al., 2004; Parikh and Sarter, 2006). These demonstrations, combined with a long history of studies identifying increases in prefrontal ACh release during attentional tasks relying on cue detection (McGaughy et al., 1996; Arnold et al., 2002; Parikh et al., 2007; St Peters et al., 2011; Howe et al., 2013; Gritton et al., 2016), support that currents recorded via choline- 
sensitive electrodes reflect ACh release from cholinergic terminals. For each trial, concentration values were analyzed over a window that covered the $5 \mathrm{~s}$ before cue onset through $10 \mathrm{~s}$ after cue. The mean choline concentration over the $2 \mathrm{~s}$ period just before cue presentation served as a pretrial baseline for statistical analyses of cue-associated activity. Changes in peak amplitude of the choline currents following cue presentation were expressed as changes from this baseline. Electrochemical data were analyzed with repeated measures ANOVA with a factor of time (i.e., the corresponding choline concentration at baseline and over the next 4 s). Post hoc pairwise comparisons used Fisher's least significant difference (LSD). The behavioral data were analyzed with a linear-mixed model with the effect of drug condition. Covariance structures were selected based on Akaike's information criterion (Verbeke and Molenberghs, 2009).

For the analysis of the electrophysiological data, all statistical analyses were limited to the data from blocks 2 and 3 (infusion and postinfusion periods). ACSF infusion blocks were used for comparison to antagonist infusions, allowing us to control for any potential impact of the infusion itself on neural activity. In some trials, electrophysiological signals contained artifacts, typically from head scratching or the headstage rubbing on the enclosure wall. To remove trials of this type from further analysis, the root mean square (RMS) was calculated for $100 \mathrm{~ms}$ bins over the trial analysis window. This consisted of the precue baseline period, the cue period, and the postcue period that extended through the reward window. Any trials where the averaged RMS exceeded 5 SDs at any time throughout a trial were rejected ( 116 total trials from nine rats or $24.5 \%$ of trials).

Event-related potential analysis. To account for subtle differences in the onset response of the visually evoked event-related potentials (ERPs) seen across trials in this task, we calculated ERP magnitude on a single trial basis (Jung et al., 2001) by subtracting the minimum from the maximum value of the local field potential within the first $300 \mathrm{~ms}$ following stimulus onset (Woodman, 2010). ERP magnitude for the population shown in all figures represents the averaged the LFPs from all detected and missed cue trials during the cue and reward presentation windows.

Power analysis. Spectral power for bar plots and statistical analysis was calculated as follows. For each frequency band of interest, power was calculated by bandpass filtering the LFP time series using window-based linear phase finite impulse response filter ("firl" in the eegfilt function from the eeglab toolbox for MATLAB; Delorme and Makeig, 2004), Hilbert transforming, and multiplying the result by its complex conjugate. The Hilbert transform yields a complex-valued time series called the analytic signal, which represents the amplitude and phase of the bandpass filtered signal at each time point (Cohen, 2014). Multiplication of the Hilbert-transformed data by their complex conjugate provides the spectral power. Time-frequency power spectrograms were obtained from the multitaper Fourier method implemented by the mtspecgramc function from the Chronux toolbox for MATLAB (Bokil et al., 2010). This approach smooths the power spectrum by obtaining multiple independent estimates of the power from the same sample via the use of tapered versions of the data. A $500 \mathrm{~ms}$ sliding window with $20 \%$ overlap was selected. Tapers were chosen to maintain a frequency smear of \pm 3 Hz. Power was then normalized by Z-scoring to the baseline power ( 1 $s$ period) immediately before cue/reward onset, separately for each trial. Ninety-five percent confidence intervals were estimated with a nonparametric bootstrap method using 1000 resamples of trials with replacement.

Nonparametric tests were used because both the ERP amplitude and $Z$-scored spectral power data were nonnormally distributed as assessed by the Lilliefors test. Power increases from baseline were tested using the Wilcoxon signed-rank tests against 0 ( $Z$-scored) with Bonferroni correction. To test drug differences in the baseline normalized power, we used the Kruskal-Wallis one-way ANOVA on ranks with Bonferronicorrected post hoc Wilcoxon rank-sum tests.

Cross-frequency coupling analysis. Phase-amplitude cross-frequency coupling (CFC) was assessed using a modulation index (MI) method (Tort et al., 2010). This metric assesses the disparity of the phase-amplitude coupling from that of a uniform distribution of amplitude over phases, normalized from 0 to 1 . Briefly, each trial was separately bandpass filtered at the phase-modulating and amplitude-modulated frequency bands with eegfilt and Hilbert-transformed to create the phase- and amplitude-frequency signals, respectively. The phase time series was derived from the angle of the phase-frequency time series. The corresponding amplitude time series was computed from the absolute value of the amplitude-frequency time series. Phase time series angles were organized into 20 bins. The corresponding amplitudes were mean averaged for each phase bin and normalized by dividing the amplitude sum over all bins. The CFC metric was defined as MI $=[\log (N)+\operatorname{sum}(P * \log (P))] /$ $\log (N)$, where $N$ is the number of phase bins, and $P$ is the normalized amplitude for each phase bin (Tort et al., 2010). The raw MI values for each trial were $Z$-scored against surrogate data, as described previously (Cohen, 2008), to reduce the incidence of false coupling due to overall power changes. Two hundred (for plotting) or 1000 (for statistics) surrogate data sets were created by shifting the amplitude time series of each trial by a random amount selected from a uniform distribution. The $Z$-scored MI (zMI) was normalized by subtracting the baseline zMI for comparison across drug and behavioral conditions. Bar plots and statistical testing for the baseline-subtracted zMI followed the same procedure as for the $Z$-scored spectral power.

Intertrial phase coherence analysis. Intertrial phase coherence (ITPC) was analyzed based on the method of Cohen (2014) using our own code framework to permit comparable statistical analysis to that of power and cross-frequency coupling. The ITPC was calculated for each time-frequency window analyzed for power and CFC for each mouse. The mean ITPC of the $1 \mathrm{~s}$ baseline before cue was subtracted from the given window's ITPC over time. Baseline-normalized ITPC values ranged from -1 to 1 and were Fisher $z$-transformed using atanh(itpc) to map them to a normal distribution. These data were averaged over each time window to provide one sample for each combination of mouse, window, block, and drug.

\section{Results}

\section{Detected cues evoke ACh transients}

Analysis of the averaged amperometric currents across the first $4 \mathrm{~s}$ surrounding cue presentation showed, as demonstrated previously (Parikh et al., 2007; Howe et al., 2013), that detected cues evoked transient increases in cholinergic currents. Such currents were observable on individual trials (Fig. $3 A$ ) and in the overall mean across trials (Fig. $3 B$; baseline through $4 \mathrm{~s}$ after cue; main effect of time, $\left.F_{(9,252)}=3.65, p=0.01\right)$. This increase reached levels statistically greater than baseline by $1.5 \mathrm{~s}$ after cue and remained elevated until the reward period (post hoc LSD, baseline vs time point $1.5-3.0 \mathrm{~s}$ after cue, all $p \leq 0.01$ ) before returning to baseline levels (all $p>0.08$ ). Additional analyses compared cholinergic currents before reward and through reward delivery and retrieval and confirmed that reward receipt did not further evoke cholinergic activity (reward baseline through $4 \mathrm{~s}$ after reward; $\left.F_{(9,252)}=1.51, p=0.22\right)$. During trials in which cues were missed, currents did not change during cue presentation (Fig. 3B; main effect of time, $\left.F_{(9,90)}=0.24, p=0.75\right)$ or reward presentation and retrieval $\left(F_{(9,90)}=1.54, p=0.22\right)$. Thus, as seen here and in previous studies (Parikh et al., 2007, Howe et al., 2013), choline currents rise selectively following the presentation of a detected cue, but before reward delivery, peaking and then decaying over several seconds. Choline oxidase-based amperometry represents the current state of the art for characterizing fast changes in ACh release; however, the sampling rate $(2 \mathrm{~Hz})$ may have limited the extent to which true rise and decay kinetics of phasic ACh release events could be precisely characterized (for further discussion of the significance of rise and peak times, see Sarter et al., 2016). Using the same type of platinum microelectrode array used for electrochemistry, we next characterized changes in the local field potential during cue detection. 
A

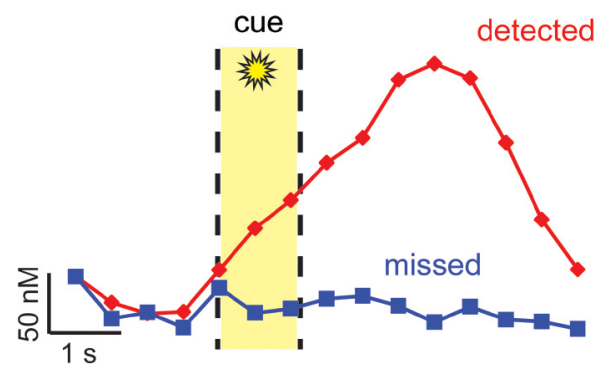

B

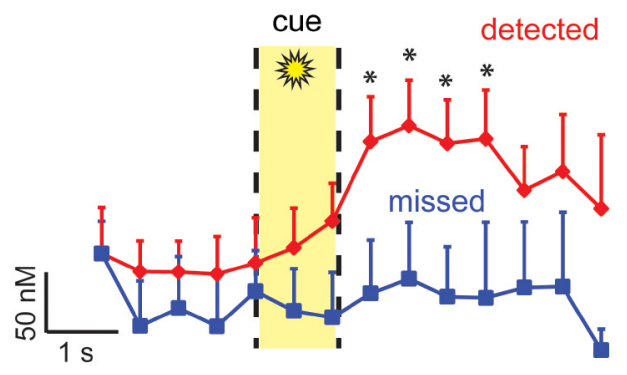

Figure 3. Confirmation of cue-evoked phasic ACh release when cues are detected, but not missed. Fixed-potential amperometry was used to measure choline currents in the right PFC of animals performing a cued appetitive response task ( $n=2$; field potentials were recorded using the same electrodes). $\boldsymbol{A}$, Example of single trials showing changes in choline currents on a trial where the cue was detected (red) and a trial when the cue was missed (blue). For each trace, the first data point has been set to 0 , and each subsequent point reflects the change in choline concentration from this point. The yellow shaded area represents the $1 \mathrm{~s}$ cue presentation window. $\boldsymbol{B}$, Population average of choline currents observed during detected ( 29 trials) versus missed cues (11 trials). Choline currents began to rise with the onset of the cue, but only when such cues were detected. Currents reached their peak within seconds, and then began to decline before reward presentation $6 \pm 2 \mathrm{~s}$ later. These results confirm our prior findings supporting a selective role for phasic ACh release in cue detection (Parikh et al., 2007; Howe et al., 2013). Error bars indicate SEM. ${ }^{*} p<0.05$ versus precue choline concentrations.

\section{Detected cues evoke synchronous neural activity across multiple frequencies}

Task-relevant stimuli have been shown to trigger changes in the LFP that can be quantified both at the level of ERPs and through changes of power within discrete frequency bands (Narayanan et al., 2013; Nguyen and Lin, 2014; Laubach et al., 2015). We first explored whether or not cue presentation evoked a LFP change in the PFC and then further investigated changes within specific frequency bands and within this same time period. We focused our analyses around the two salient stimuli in the cued appetitive response task, the visual cue and reward delivery, for trials ending with hits and misses. We found that detected and missed cues generated dissociable patterns of oscillations within the LFP, and that this could be visualized on a single trial basis. Representative spectrograms from a single detected cue trial and single missed cue trial are plotted in Figure 4, $A$ and $B$, respectively. To further analyze this observation, we compared the spectral power on detected and missed trials in $500 \mathrm{~ms}$ bins from cue onset to reward delivery across four major frequency bands that have been implicated in sensory processing and cognitive function: gamma $(\sim 30-100 \mathrm{~Hz})$, beta $(\sim 12-30 \mathrm{~Hz})$, theta $(\sim 5-12 \mathrm{~Hz})$, and delta (2-5 Hz; Bland and Oddie, 2001; Fries et al., 2001; Lakatos et al., 2005; Womelsdorf and Fries, 2007; Tort et al., 2009; Cruikshank et al., 2012; Leventhal et al., 2012; Newman et al., 2013).

Animals detected the majority of cues $(82.85 \pm 8.04 \%)$ in the cued appetitive response task. On detected trials, cues produced a reliable change in the cue triggered LFP (Fig. 6A) and significant changes in three of the four spectrally dissociable frequency bands during the cue detection window (for a visualization of the changes in power in these frequency bands across trials from a single session and animal, see Fig. $5 B, C$ ). All statistical tests for the LFP analyses used a Bonferroni correction for multiple comparisons. Delta (Wilcoxon signed-rank test against zero power, $Z=0.73, p<0.001$ ) and theta (Wilcoxon signed-rank test against zero power, $Z=0.79, p<0.001$ ) were both significantly elevated during the first $500 \mathrm{~ms}$ of the cue. Gamma, in contrast, was significantly elevated in both the $0-500 \mathrm{~ms}$ window (Wilcoxon signed-rank test against zero power, $Z=0.17, p<0.001$ ) and the 500-1000 ms window of the cue (Wilcoxon signed-rank test against zero power, $Z=0.31, p<0.001)$.

Upon closer inspection, we found that the power increase in delta was centered at $2-5 \mathrm{~Hz}$, between 7 and $12 \mathrm{~Hz}$ for theta, and from 75 to $90 \mathrm{~Hz}$ in the gamma band during the first $300 \mathrm{~ms}$ of a detected cue (Fig. 6C). Following this initial burst in local highfrequency gamma synchrony, both theta and delta power diminished, and gamma power transitioned to a lower frequency centered between 47 and $57 \mathrm{~Hz}$ from 500-1000 ms after cue presentation. Moreover, the increased power at $47-57 \mathrm{~Hz}$ persisted throughout the interval between cue offset and reward delivery (500 to $3000 \mathrm{~ms}$ after cue; Wilcoxon signed-rank test, $Z=0.37, p<0.001$; Figs. $6 C, 7 B)$, covering the time period in which animals initiated a reward port approach (average latency from cue to initiation of approach, $2.28 \pm 0.28 \mathrm{~s}$ ). Only detected cues were associated with this specific pattern of oscillatory activity. Increases in power over baseline in the 7-12 Hz (Wilcoxon signed-rank test, $Z=0.56, p=0.04$ ) and 75-90 Hz (Wilcoxon signed-rank test, $Z=0.18, p=0.04$ ) bands were also observed in the first $300 \mathrm{~ms}$ after cue onset on missed trials (Fig. 6E). Cue presentation on trials that resulted in a miss lacked the increases in low gamma synchrony observed when cues were detected (47-57 Hz; Fig. 6E, Wilcoxon signed-rank test, $p>0.05$ ).

Reward was delivered on every trial, regardless of the animal's response to the cue. We analyzed the period surrounding reward delivery and retrieval on hit and miss trials to identify what changes in prefrontal oscillatory activity were unique to the detection of a predictive cue versus those that might reflect the sudden presentation of any salient environmental stimulus. No statistically significant time-frequency modulation was evident during reward presentation for any of the time-frequency bands identified as cue modulated above (for an example across trials in a single session, see Fig. $5 B, C$; for all results, see Fig. $6 D, F$; all Wilcoxon signed-rank test, $p>0.05$ ).

Cue presentation was also associated with a detectable broadspectrum change in the local field potential on both detected and miss trials (for the cue-triggered average LFP from detected trials in a single session, see Fig. $5 A$; for the cue-triggered population average LFP from all detected and missed trials, see Fig. $6 A$ ). We further quantified the amplitude of this change by calculating the maximal deflection of the LFP signal from minimum to maximum during the first $300 \mathrm{~ms}$ of the stimulus as the ERP. Using this analysis, we found that ERP amplitude at cue presentation did not differ between detected and missed trial types (KruskalWallis test, main effect of trial type, $p=0.66$ ). A similar analysis for reward presentation also revealed no difference between detected and missed trials $(p=0.49)$. Thus, unlike phasic ACh 
A
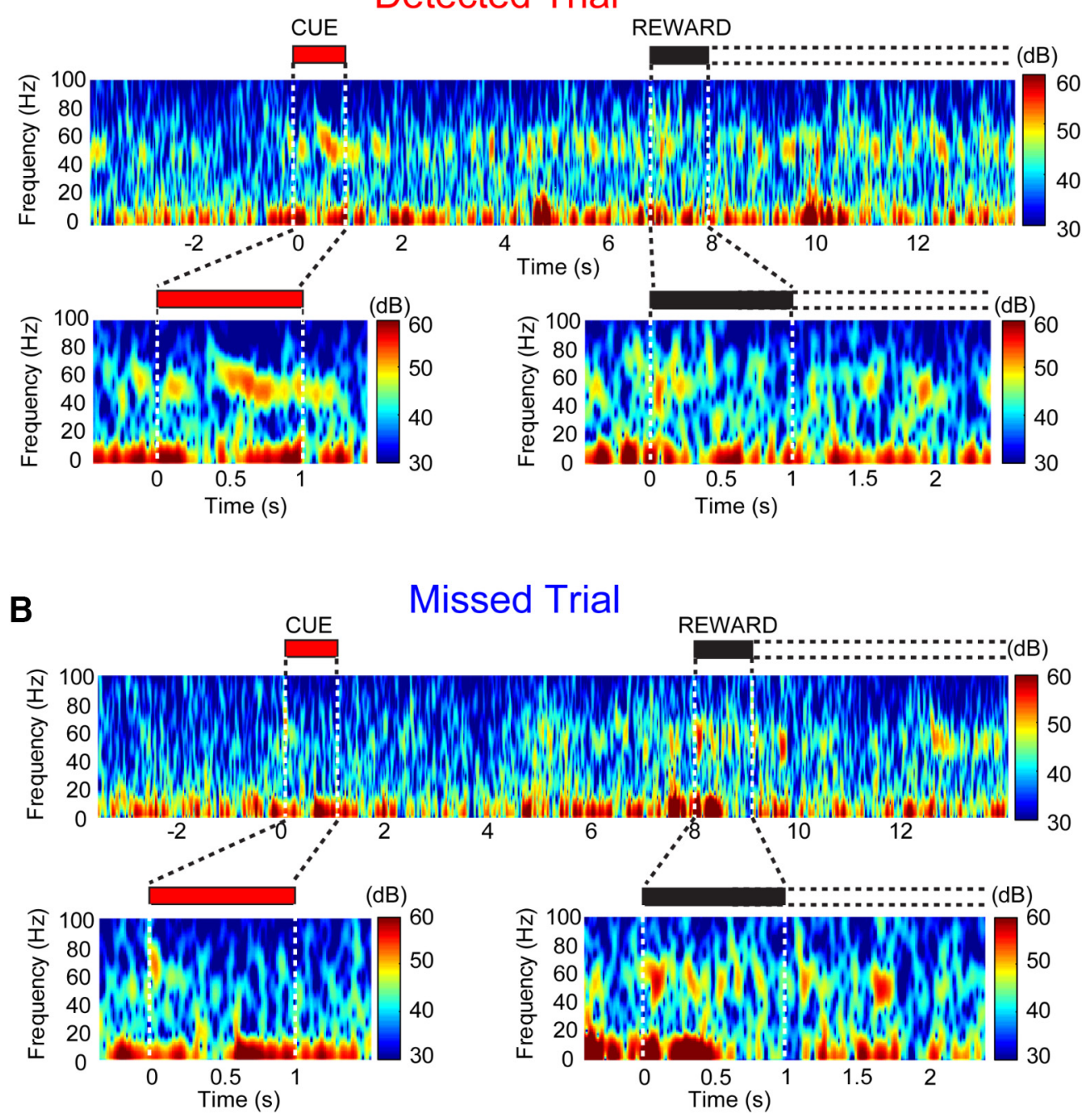

Figure 4. Dissociation of detected and missed cues in the local field potential. $A, B$, Top, Changes in spectral activity from individual detected and missed cue trials for a representative animal. Spectrograms from a single detected trial $(\boldsymbol{A})$ and a missed trial $(\boldsymbol{B})$ from the same recording session are shown, with the cue and reward periods magnified below, noted by the red and black bars, respectively. The first second after reward delivery is shaded black, with the dashed lines representing the reward availability window. The color scale to the right indicates amplitude. When cues were detected, we noted a prominent increase in high-frequency power, particularly in gamma frequency ranges (e.g., $>30 \mathrm{~Hz}$ ), that persisted for several seconds and was reliably observed across individual trials. Changes in LFP power coincided with cue detection in lower-frequency bands $(<20 \mathrm{~Hz})$ with different temporal profiles $(\boldsymbol{A})$. Such changes high-frequency power were not apparent when cues were missed $(\boldsymbol{B})$, or when reward was presented on either trial type.

release and oscillations, ERPs in the present task were not unique to cue detection.

\section{Cholinergic modulation of oscillations during cue detection}

As reported previously and observed here, detected cues evoked phasic increases in prefrontal ACh release (Parikh et al., 2007; Howe et al., 2013). To identify what components of the local field potential changes associated with cue detection might be modulated by such transient increases in ACh release, we recorded from the right $\mathrm{PFC}$ of the animals performing the cue detection task while either the high-affinity M1 muscarinic receptor antagonist, telenzepine ( $50 \mathrm{nmol}$ in $1 \mu \mathrm{l}, 50 \mathrm{nl} / \mathrm{min}$ infusion rate), or the nicotinic receptor antagonist, mecamylamine $(2 \mathrm{nmol}$ in $1 \mu \mathrm{l}$, $50 \mathrm{nl} / \mathrm{min}$ infusion rate), was locally infused, unilaterally, into the recording area. Given that silencing of phasic ACh release in a subregion of the PFC is not sufficient to block cue detection (Gritton et al., 2016), we likewise did not anticipate that local antagonist infusions would increase the number of misses. Rather, the goal was to infuse sufficient concentrations of each compound to antagonize the targeted receptor population near the electrode to better understand the unique contribution of the different receptor subtypes to the changes in the LFP associated with cue detection.

Behaviorally, local infusion of cholinergic antagonists into right PFC alone was not sufficient to alter task performance, as expected (linear mixed model comparing ACSF, telenzepine, and mecamylamine detection rates, main effect of drug; $F_{(2,3.95)}=1.94, p=0.26$ ). However, it is noteworthy that infusions of the M1 antagonist telenzepine yielded a trend toward more misses (percentage of cues detected, mean \pm SEM, ACSF, $82.86 \pm 7.47 \%$; telenzepine, $65.12 \pm$ $10.41 \%$; mecamylamine, $80.00 \pm 9.65 \%$; Fig. $7 A$ ). The amplitude of ERPs associated with cue presentation did not differ on detected and miss trials (above), and we further found no evidence to suggest that such ERPs were altered by telenzepine or mecamylamine on detected (Fig. $8 A$; Kruskal-Wallis test, main effect of drug, $p=0.78$ ) or missed (Fig. $8 E$; Kruskal-Wallis test, main effect of drug, $p=0.21$ ) cues. Cholinergic receptor blockade at the recording site did, however, significantly impact the prefrontal oscillatory activity 
A

\section{CUE ONSET}
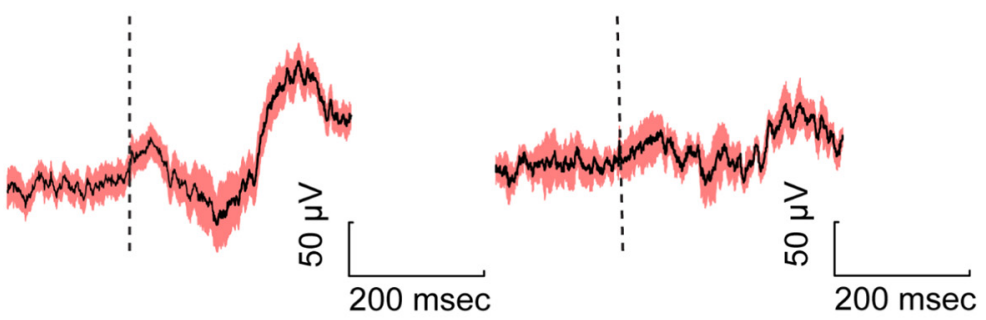

\section{REWARD ONSET}

B

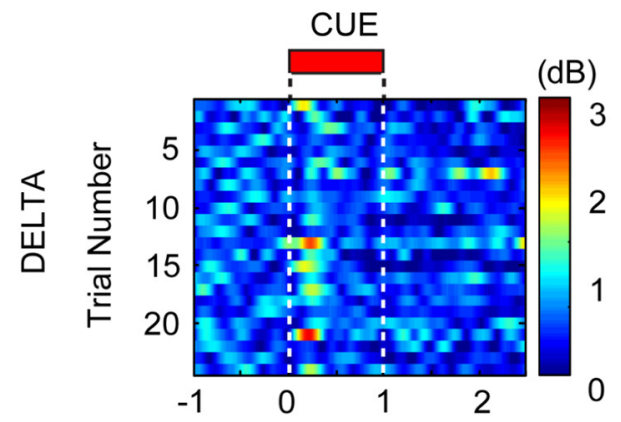

$(\mathrm{dB})$
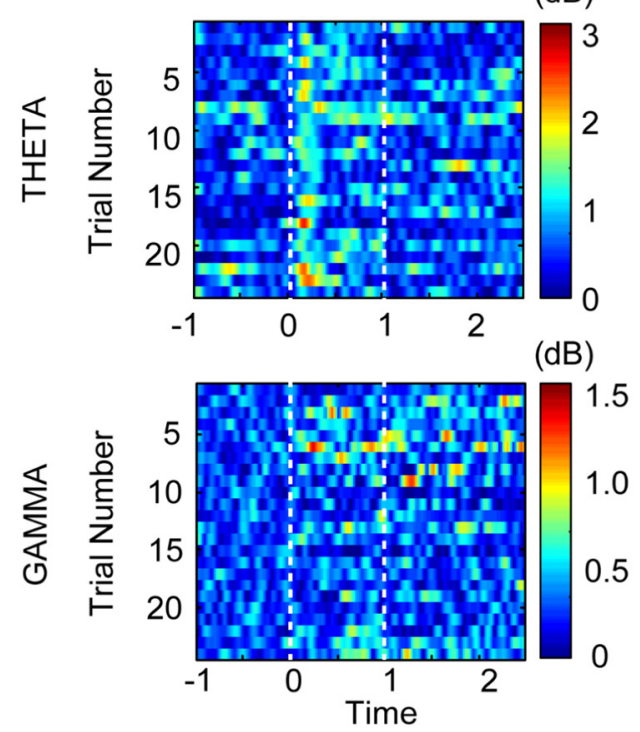

C

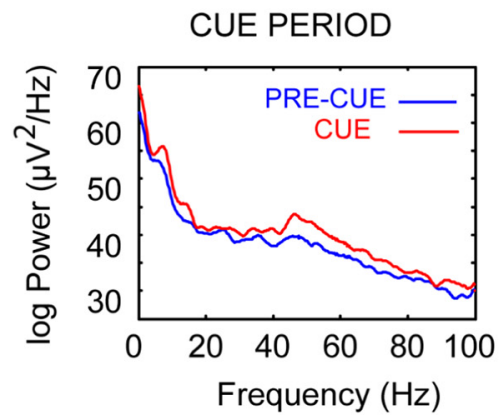

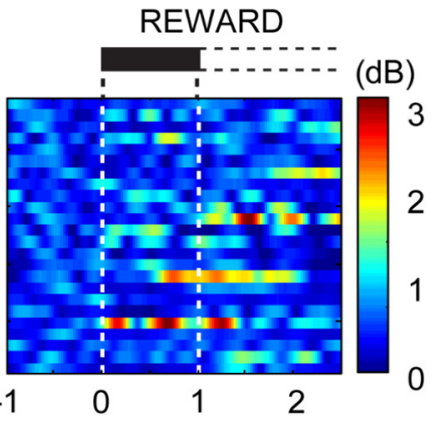

(dB)

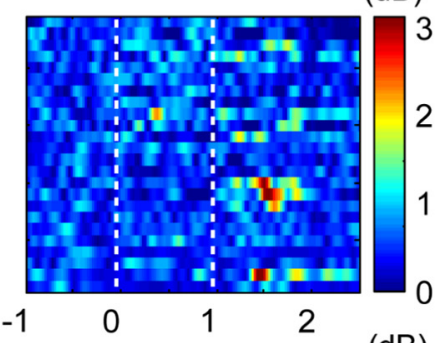

(dB)

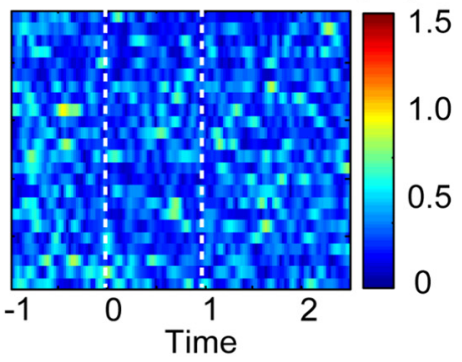

REWARD PERIOD

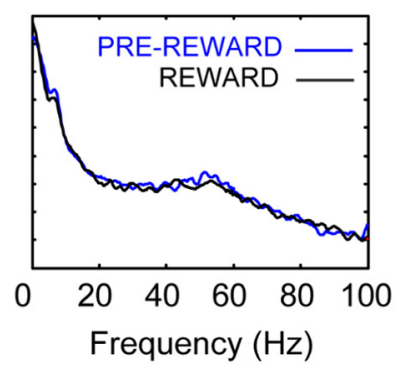

associated with cue detection. Of the four dissociable frequency bands described above that were identified as being modulated by cue detection, the effects of cholinergic receptor blockade were specific to oscillations in the low gamma $(47-57 \mathrm{~Hz})$ and high gamma ranges $(75-90 \mathrm{~Hz}$; Fig. $7 B-D)$.

Infusions of the M1-selective mAChR antagonist telenzepine attenuated detected cue-evoked high gamma synchrony in the first $300 \mathrm{~ms}$ of cue presentation (Figs. $7 C$, $8 B$; Kruskal-Wallis test, main effect of drug, $\chi_{(2,247)}^{2}=7.67, p=0.02$, telenzepine vs vehicle; Wilcoxon rank-sum test, $p=0.001$ ). Telenzepine further attenuated the detected cue-evoked shift to low gamma synchrony during the $500-1000 \mathrm{~ms}$ window during the cue period (main effect of drug administration on power, Kruskal-Wallis test, $\chi_{(2,247)}^{2}=$ $6.13, p=0.046$, telenzepine vs vehicle; Wilcoxon rank-sum test, $p=0.03$; Fig. $8 C, D)$. The effects of telenzepine were specific to the detected cue period, and had no impact on power on the theta and high gamma power observed during the cue on misses (Fig. 8F, G; Kruskal-Wallis test across drugs for each frequency, $p>0.05$ ).

As observed following telenzepine administration, mecamylamine attenuated detected cue-evoked high gamma synchrony in the first $300 \mathrm{~ms}$ of cue presentation (mecamylamine vs vehicle; Wilcoxon rank-sum test, $p=0.04$; Figs. $7 D, 8 B$ ). In contrast to the effects of telenzepine, mecamylamine administration did not attenuate the increase in detected cue-evoked low gamma activity during the 500-1000 ms cue period (mecamylamine vs vehicle; Wilcoxon rank-sum test, $p>0.05$; Fig. $8 D$ ), and furthermore, low gamma synchrony remained higher in the presence of mecamylamine relative to that observed in the presence of telenzepine (mecamylamine vs telenzepine; Wilcoxon rank-sum test, $p=$ 0.01). Mecamylamine had no impact on power in the theta and high gamma bands observed during the cue on misses (Fig. $8 F, G$; Kruskal-Wallis test across drugs for each frequency, $p>0.05$ ).

As noted above, cues that were detected and those that were missed differed predominantly in terms of the highfrequency synchrony evoked by cue presentation. We next directly tested whether

$\leftarrow$

Figure 5. Detected cues modulate power in select frequency bands. A, Averaged cue-triggered LFP aligned to cue and reward onset across trials from a single session in a single animal. $\boldsymbol{B}$, Bandpass-filtered Hilbert-transformed LFP color plots for all detected trials $(n=24)$ for the cue and reward periods from a single session. Plots illustrate the three frequency bands that showed significant changes coincident with cue detection: delta $(2-5 \mathrm{~Hz})$, theta $(7-12 \mathrm{~Hz})$, and gamma $(47-57 \mathrm{~Hz})$. C, FFT power spectrum from all trials shown in $\boldsymbol{B}$ for the $1 \mathrm{~s}$ cue period (left, red) plotted in comparison to power in the $1 \mathrm{~s}$ window before cue (blue). The reward period is shown on the right with the FFT power representing the first second of available reward (black) compared to the $1 \mathrm{~s}$ prereward period (blue). Power has been Z-score normalized to the precue period. 
A

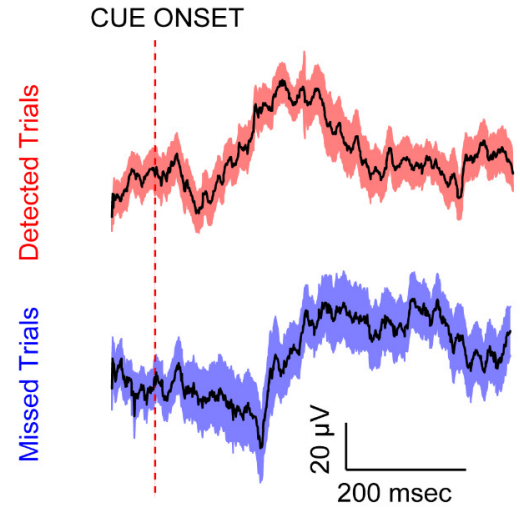

C
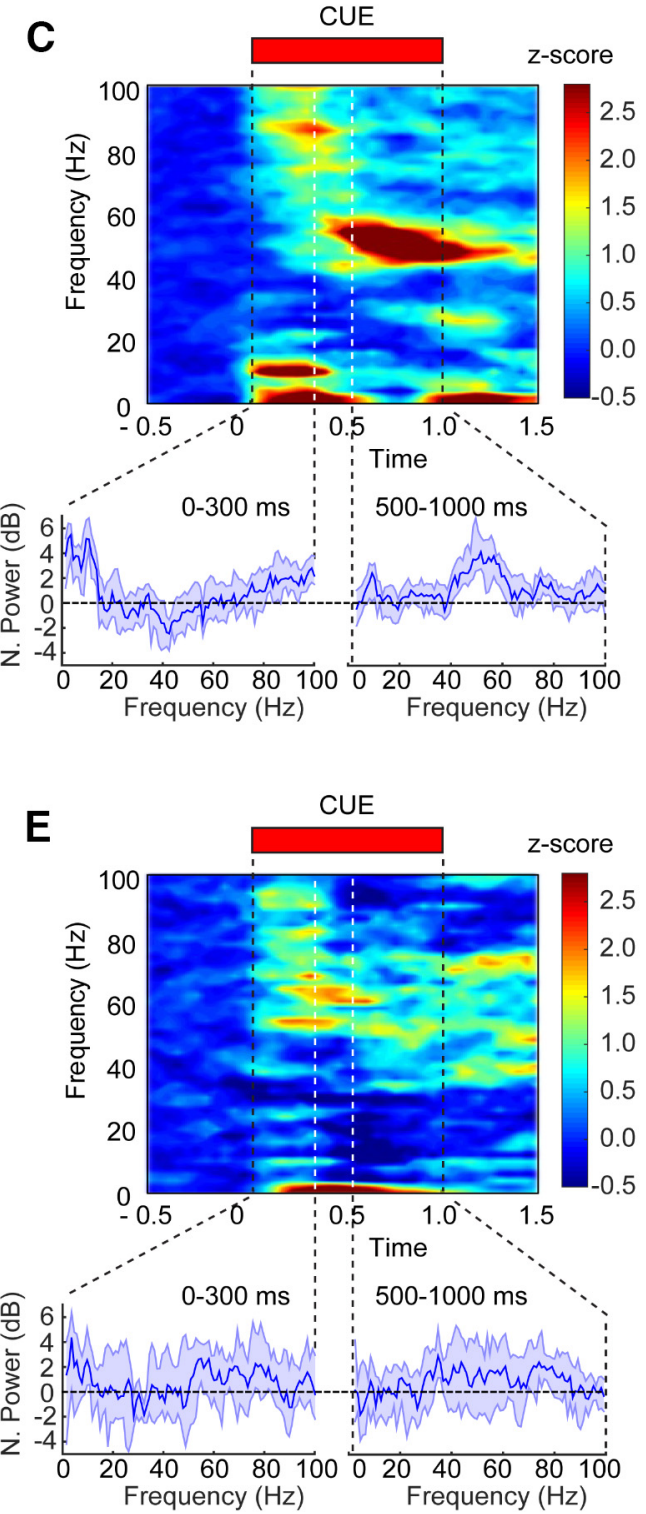

B REWARD ONSET
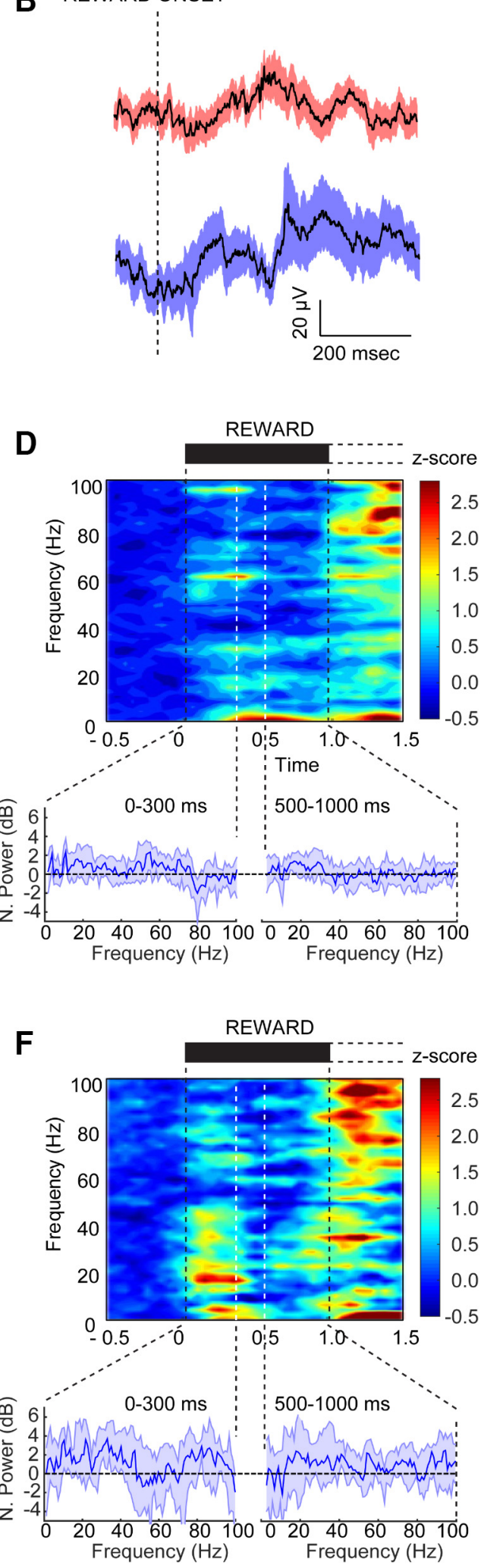

Figure 6. Cue detection is represented by oscillations in the LFP. $A, B$, Cue- and reward-triggered changes in the LFP from detected ( $n=7$ animals, 63 trials) and missed trials $(n=24$ trials) in blocks 2 and 3 for all ACSF-infused animals. Broad-spectrum LFPs did not differ substantially on detected and missed trials. C-F, Cue- and reward-triggered changes in neural oscillations from the same trials. The power spectrum from the highlighted period above is shown below each spectrogram. The left spectrum represents time points $0-300 \mathrm{~ms}$ after cue, and the right spectrum represents time points 500-1000 ms after cue. C, Spectrogram for the cue window when such cues were detected. Detected cues selectively evoked increases in delta, theta, and high gamma oscillations in the early phase of cue presentation, and sustained low gamma oscillations in the late phase. $\boldsymbol{D}$, Population spectrogram from the reward-presentation period for the detected trials shown in $\boldsymbol{C}$ with the corresponding spectrum below. $\boldsymbol{E}$, Cue-triggered population spectrogram for missed trials. Missed cues were associated with increased theta and high gamma power but lacked the low gamma power increases during the late phase of cue presentation. $\boldsymbol{F}$, Reward-triggered population spectrogram corresponding to the same trials shown in $\boldsymbol{E}$. Power was $Z$-score normalized to the $1 \mathrm{~s}$ before cue/reward. Error bars represent the $95 \%$ confidence intervals for the median Z-scored power. 
muscarinic or nicotinic receptor antagonism recapitulated the oscillatory signature of a missed cue. Specifically, power in the high and low gamma bands during detected trials in the presence of the cholinergic antagonists was compared with cues that were missed in the ACSF condition. With respect to high gamma, power was greater during detected cues relative to cues that were missed [Kruskal-Wallis test, main effect of condition (drug or miss), $\chi_{(3,270)}^{2}=7.72, p=0.05$, hit vs miss; Wilcoxon rank-sum test, $p=0.04]$. Both local $\mathrm{nAChR}$ and $\mathrm{mAChR}$ antagonism attenuated high gamma synchrony to levels that did not differ from that seen during a miss (Wilcoxon rank-sum test, $p>0.05$ ). The effects of telenzepine were even more robust, reducing high gamma power below that observed in the presence of mecamylamine (Wilcoxon rank-sum test, $p=0.04$ ). For low gamma synchrony, cue-evoked normalized power was lower for a miss than for a hit during the second $500 \mathrm{~ms}$ of cue presentation [KruskalWallis test, main effect of condition (drug or miss), $\chi_{(3,270)}^{2}=9.16, p=0.03$, hit vs miss; Wilcoxon rank-sum test, $p=0.01$ ]. Low gamma power associated with detected cues in the presence of telenzepine did not differ from that seen when a cue was missed (Wilcoxon rank-sum test, $p>$ $0.05)$. In contrast, low gamma power in the presence of mecamylamine remained higher than that observed during a missed cue (Wilcoxon rank-sum test, $p=0.003$ ). Together, our data support and extend previous work by highlighting a selective role for cholinergic mechanisms in the emergence and maintenance of gamma oscillations (Faulkner et al., 1998, 1999).

\section{Cholinergic receptor antagonism disrupts cue-evoked cross frequency coupling}

Cross-frequency coupling has been proposed as a means of organizing neural information processing to enhance cognitive performance (Canolty and Knight, 2010). In particular, phase-amplitude coupling is the process by which the amplitude of a high-frequency rhythm is modulated by the phase of a lowerfrequency oscillation within the LFP. Through this process, slow rhythms across cortical regions provide a means of aligning higher-frequency rhythms that reflect locally coordinated spiking events (von Stein and Sarnthein, 2000; Canolty and Knight, 2010). It is therefore possible that CFC provides a basis for coordinating and integrating across the variable time-
A

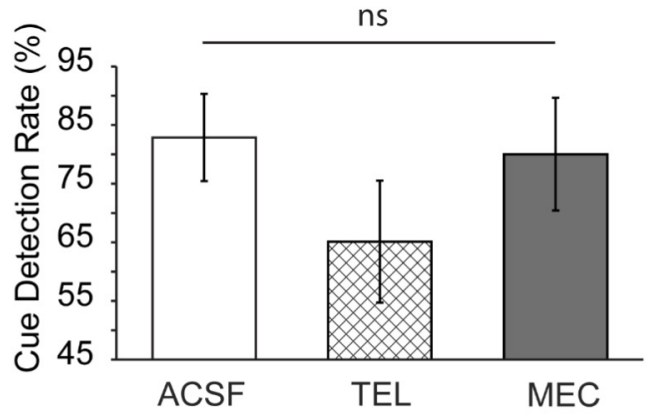

B
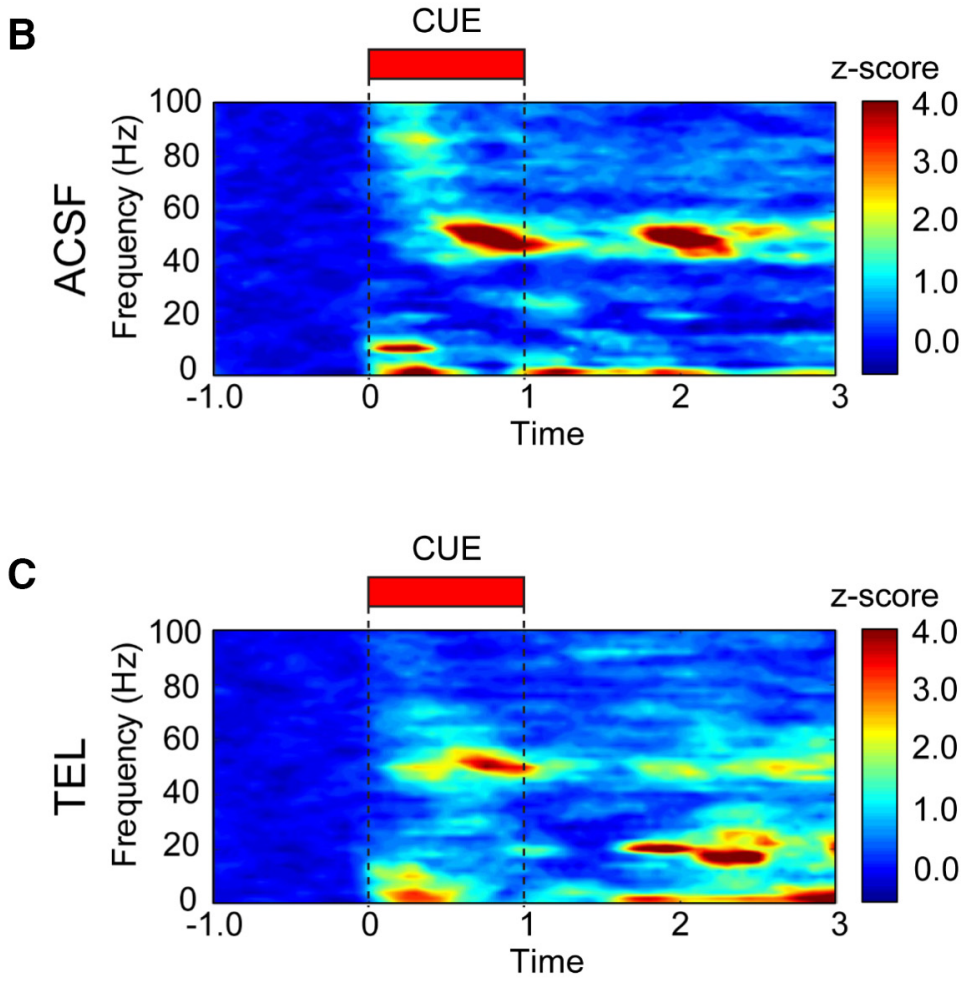

D

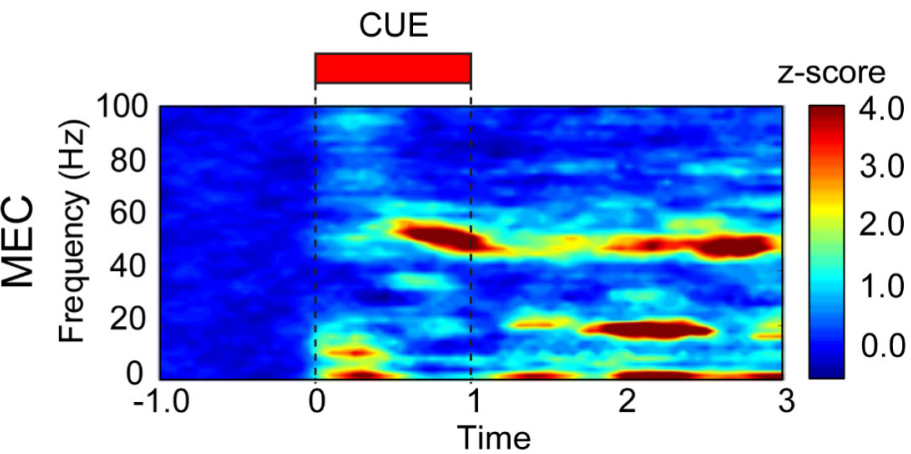

Figure 7. Cholinergic antagonist effects on performance and oscillations promoted by detected cues. $A$, Detection rates (mean \pm SEM) during the infusion and postinfusion blocks separated by drug type. $B$, Cue-triggered population spectrogram from detected trials for all animals during the infusion and postinfusion periods ( $n=7$ animals, 63 trials). An increase in gamma, theta, and delta power is present following infusion of vehicle (ACSF). C, Cue-triggered population spectrogram from all detected trials during the infusion and postinfusion periods ( $n=9$ animals, 94 trials) for telenzepine (TEL). Telenzepine reduced early high gamma power as well as the sustained increase in gamma power that persisted to the reward period. $\boldsymbol{D}$, Cue-triggered population spectrogram from all detected trials during the infusion and postinfusion periods ( $n=8$ animals, 93 trials) for mecamylamine (MEC). Mecamylamine reduces high-frequency gamma at cue onset but has no influence on low gamma, theta, or delta power. Power has been Z-score normalized to the precue period for all spectograms. 
B

\section{Detected Trials}

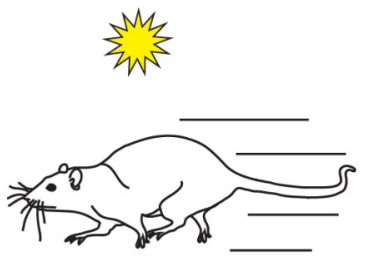

A

ERP Amplitude

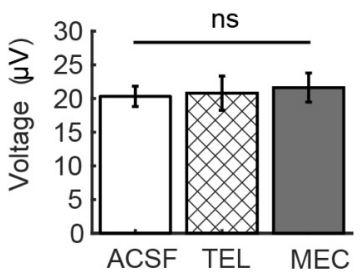

\section{Missed Trials}

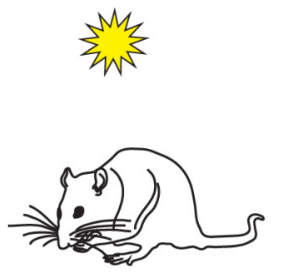

E
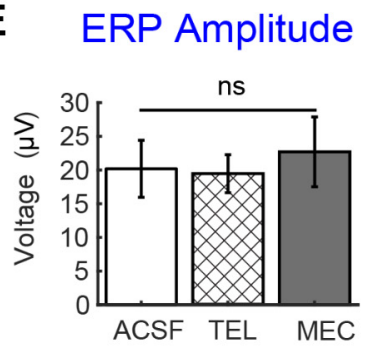

$\mathbf{F}$
LFP Power (early)

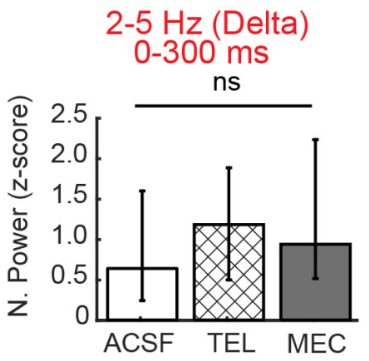

7-12 Hz (Theta) $0-300 \mathrm{~ms}$
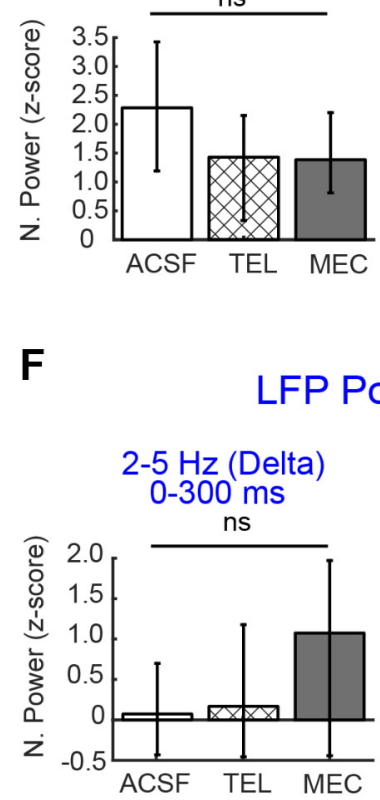

LFP Power (early)

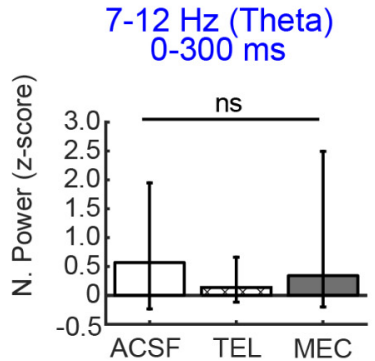

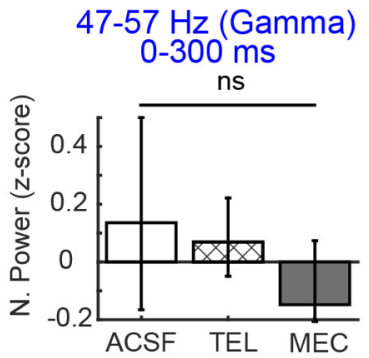
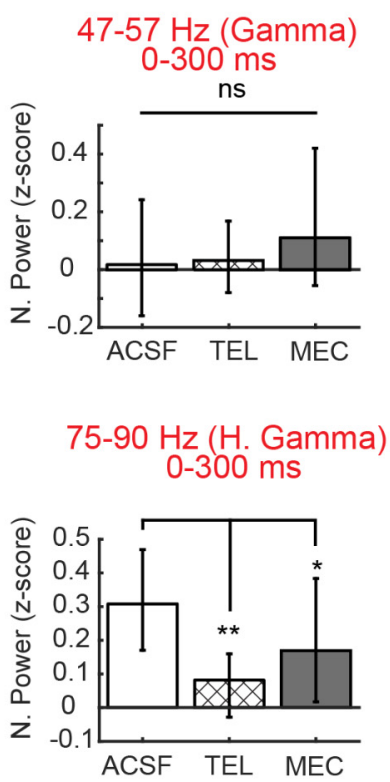

G LFP Power (late)
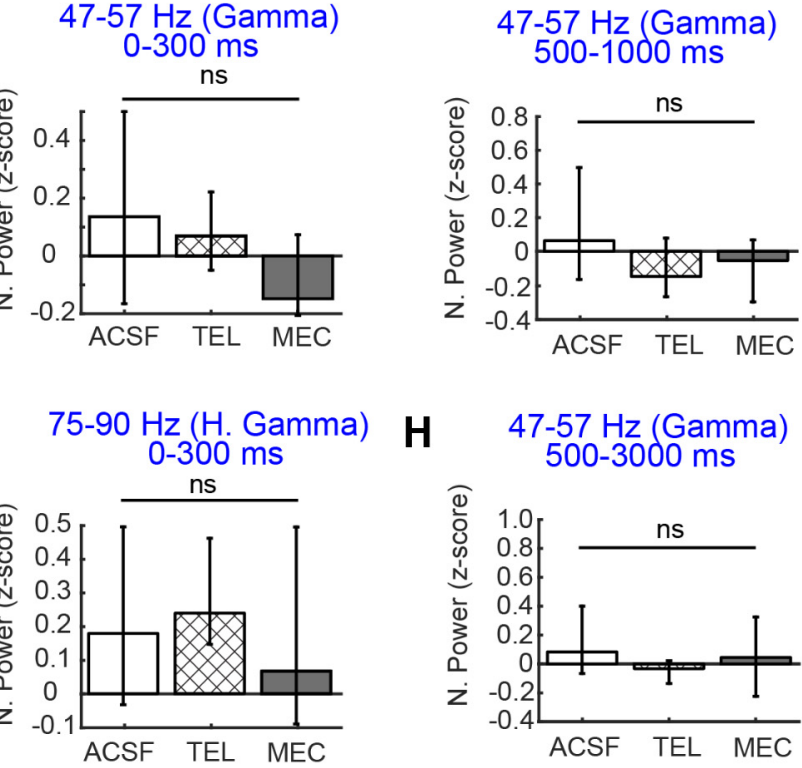

C LFP Power (late)

47-57 Hz (Gamma) 500-1000 ms

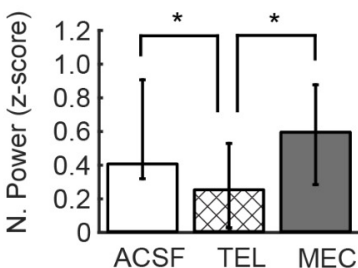

D $\quad \begin{gathered}47-57 \mathrm{~Hz}(\text { Gamma) } \\ 500-3000 \mathrm{~ms}\end{gathered}$

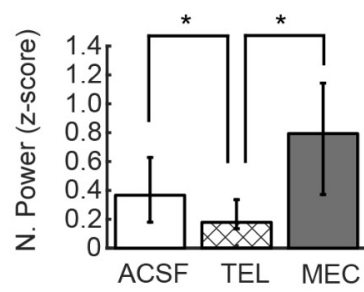

Figure 8. Bar plots quantifying the reduction in power shown in the population spectrograms across the three frequency ranges during cue presentation on detected and missed trials. $A$, ERP amplitude associated with the visual cue was not influenced by local cholinergic receptor antagonism. $\boldsymbol{B}$, During the first $300 \mathrm{~ms}$ of cue presentation on detected trials, power in the high gamma frequency was reduced by both the mAChR (M1) antagonist telenzepine (TEL) and the nAChR receptor antagonist mecamylamine (MEC). $C, D$, Normalized gamma power during the late phase of the cue window (C; $500-1000 \mathrm{~ms})$ and the 2 sfollowing the cue and before reward delivery ( $\boldsymbol{D} ; 500-3000 \mathrm{~ms})$ was selectively reduced by telenzepine. $\boldsymbol{E}-\boldsymbol{H}$, Effects of cue presentation on ERP amplitude $(\boldsymbol{E})$ and LFP power $(\boldsymbol{F}-\boldsymbol{H})$ on missed trials. Missed cues lacked the robust changes in high and low gamma power seen during detected cues. Neither cholinergic receptor antagonist affected the residual power observed in these frequency ranges. Error bars represent the $95 \%$ confidence intervals for the median $Z$-scored power. ${ }^{*} p<0.05$; ${ }^{* *} p<0.01$.

scales of cognitive operations recruited during behavioral performance. Recent studies have indicated that systemic manipulation of the cortical cholinergic system can potently modulate the formation of synergistic phase-amplitude relationships (Newman et al., 2013). Given the effects of mAChR and nAChR antagonists on detected cue-evoked gamma oscillations observed here, we explored the impact of such receptor blockade on potential CFC in the context of detected cues.
In ACSF-infused animals, we first explored whether the increase in high gamma and theta power during the first $300 \mathrm{~ms}$ of cue presentation on detected trials coincided with gamma amplitude coupling to theta phase. Although power was strongly increased in both frequency bands during this window, there was no significant high gamma $(75-90 \mathrm{~Hz})$ amplitude coupling to the theta phase (Fig. 9D; 7-12 Hz; Wilcoxon signed-rank test against zero CFC change from baseline, $p=0.45$ ). Delta power was also 
A
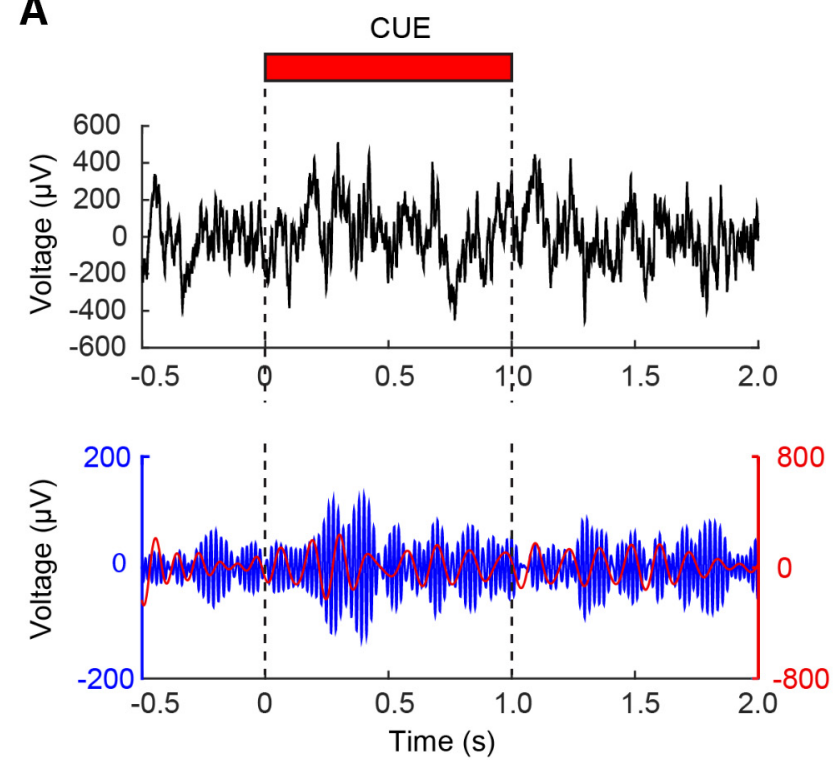

C
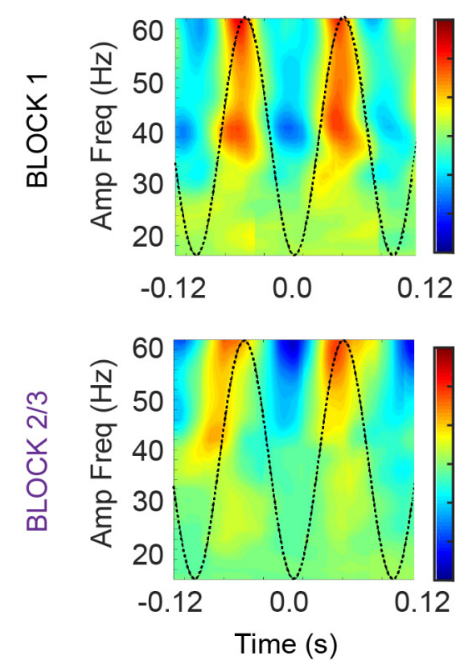

TEL
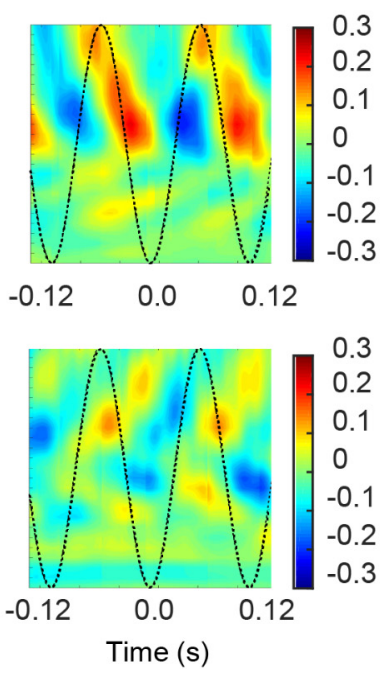

B
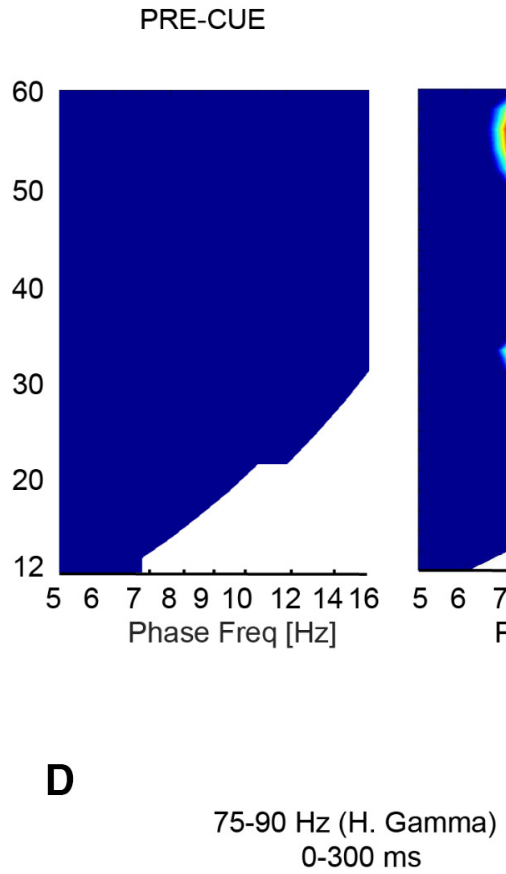

CUE

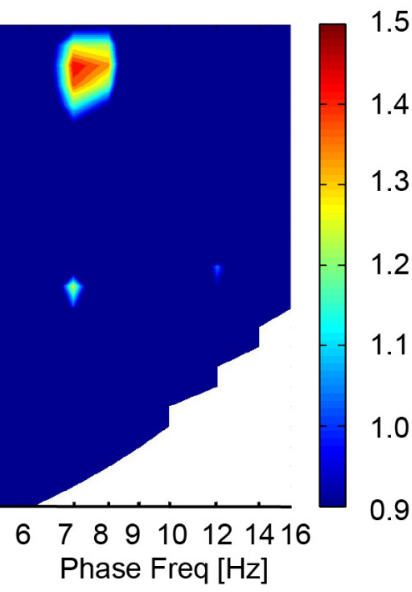

D
47-57 Hz (Gamma) $500-3000 \mathrm{~ms}$
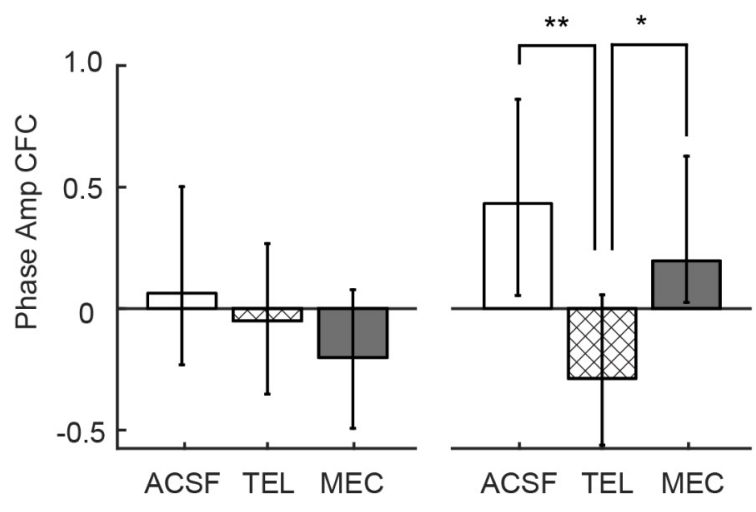

Figure 9. Gamma and theta exhibit phase-amplitude cross-frequency coupling following detected cues. $\boldsymbol{A}$, Single trial example of raw LFP (top) and bandpass-filtered LFP for theta (red) and gamma (blue). Note the increase in gamma power is phase aligned at theta peaks beginning $\sim 500 \mathrm{~ms}$ into cue presentation and extends into the delay period before reward delivery. $\boldsymbol{B}$, Population CFC comodulograms from the precue (left) and late cue/postcue periods ( $500-3000 \mathrm{~ms}$; right) for all ACSF-infused animals during the infusion and postinfusion blocks ( $n=7$ animals, 63 trials). CFC coupling in the postcue window was normalized to the precue CFC shown on the left. C, Illustration of the capacity of telenzepine (TEL) to potently disrupt the CFC phase relationship between gamma and theta during cue presentation and reward retrieval. Individual phase-amplitude plots from a representative animal showing gamma power modulation as a function of theta phase from the preinfusion (block 1; top) and postinfusions (block 2/3; bottom) periods in the presence of ACSF (left) and telenzepine (right). D, Population histogram showing median precue subtracted theta- gamma CFC strength of coupling following infusion. Coupling strength for high gamma-theta in the first $300 \mathrm{~ms}$ is shown on the left, and low gamma-theta is shown on the right. Note

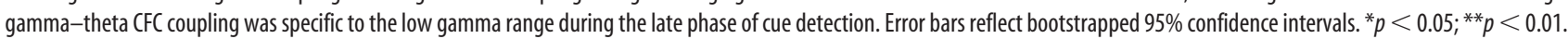

elevated during the early phase of cue detection, coincident with both periods of theta and high gamma. Therefore, we also tested for coupling between these frequencies. To measure amplitude coupling, we extended the analysis window slightly to $0-500$ and $0-1000 \mathrm{~ms}$ to include the necessary one or more full cycles of the low-frequency oscillation (Tort et al., 2010; Wang et al., 2012; Newman et al., 2013). We found no evidence of significant coordination between delta and high gamma during the early phase of the cue (first $500 \mathrm{~ms}$; Wilcoxon signed-rank test, $p=0.50$ ) or the entire cue window (1000 ms; $p=0.93$ ). To analyze delta and theta coordination, we needed to limit the ranges of each fre- quency band to avoid overlap $(2-4 \mathrm{~Hz}$ for delta and $8-12 \mathrm{~Hz}$ for theta). There was no significant relationship between these lower-frequency bands during cue detection (first $500 \mathrm{~ms}, p=$ $0.93 ; 1000 \mathrm{~ms}, p=0.49$ ).

We next analyzed the 500 to $3000 \mathrm{~ms}$ postcue window where a persistent increase in low gamma power was observed. During this window, corresponding to the time when the decision to use the information provided by the cue is made, low gamma (47-57 $\mathrm{Hz})$ amplitude was coupled to theta phase $(7-12 \mathrm{~Hz}$; Wilcoxon signed-rank test, change from baseline, $Z=0.42, p=0.03)$. This coupling was observable across individual trials (Fig. 9A), indi- 
vidual sessions (Fig. 9C), and across the population (Fig. 9B). Cues that were missed were not associated with theta-gamma coupling (Wilcoxon signed-rank test, $Z=0.12, p=0.80$ ). An additional analysis of delta-gamma coupling in the 500 to 3000 $\mathrm{ms}$ window provided no evidence of coordination between these frequencies during this same time period $(p=0.45)$. Therefore high-frequency coupling to lower frequencies during cue detection was specific to theta and low gamma.

The cue-evoked theta-gamma CFC increase above baseline was no longer detectable following the administration of the M1 receptor antagonist, telenzepine (Wilcoxon signed-rank test, $p>$ 0.05 ), and further remained lower than that observed during cue detection on ACSF trials (Kruskal-Wallis test, main effect of drug, $\chi_{(2,247)}^{2}=9.50, p=0.01$, telenzepine vs vehicle; Wilcoxon rank-sum test, $p=0.002$; Fig. $9 D$ ). Although mecamylamine administration did not directly attenuate the persistent detection-related low gamma oscillations, it did attenuate thetagamma CFC (Fig. 9D; Wilcoxon signed-rank test against baseline, $p>0.05)$. CFC in the presence of mecamylamine did however remain higher than that observed in the telenzepine condition (mecamylamine vs telenzepine; $p=0.005$ ). Thus, the emergence of the early high gamma, which involves both $\mathrm{mAChR}$ and $\mathrm{nAChR}$ signaling, is necessary for the later coupling of theta and gamma oscillations during cue detection. Interestingly, in the two conditions where theta-gamma CFC was blocked, we noticed the emergence of a strong beta band that occurred $\sim 1.5-2.0$ $s$ after cue onset (Fig. $7 C, D)$. Whether the emergence of beta impairs theta-gamma CFC, or vice versa, is unknown. It is possible that in the absence of normal cholinergic modulation, networks of neurons that participate in coupling may organize to promote beta oscillations in the PFC.

In addition to changes in power and cross-frequency coupling, the phase of oscillations within different frequency bands can be aligned or "reset" by salient environmental cues, and may thereby facilitate cue related processing (Canavier, 2015). To determine whether cue detection in the present paradigm was associated with such phase resetting, we adapted the method of Cohen (2014) to examine ITPC. No combination of window, block, or drug yielded a significant change in ITPC over baseline for either cue or reward presentation for hit or miss cues (all $p>$ $0.05)$. The contribution cholinergic signaling to prefrontal oscillations appears, at least in the present studies, to be specific to enhancing gamma oscillations and theta-gamma coupling during cue detection.

\section{Discussion}

Cue detection has been defined as including stimulus-triggered (re)orientation, incorporation of the information imparted by a predictive stimulus into the ongoing decision-making process, and the mobilization of a response (Posner et al., 1980; Sarter et al., 2016). The path from perception to the emergence of behavior depends on the PFC, where phasic ACh release mediates this overall change from idling to action when cues are detected (Gritton et al., 2016). The goal of the present experiments was to determine how these components of cue detection are reflected in the local field potential of the PFC and to discern the contributions of ACh release to these events.

We first confirmed that detected, but not missed, cues evoked phasic ACh release, as reported previously (Parikh et al., 2007; Howe et al., 2013). We then explored what changes in neuronal activity might be triggered by such ACh release. Several studies have implicated low-frequency (delta and theta) oscillations, along with event-related potentials in medial PFC supporting cue driven decision making (Narayanan et al., 2013; Laubach et al., 2015). While we did observe cue detection was associated with increases in low-frequency power and an ERP, we found no evidence for a role of ACh release in the PFC in these changes. Rather, we found a selective role for ACh in the emergence of high-frequency oscillations and their coordination with other frequencies through phase amplitude coupling. Specifically, we discovered that detected cues were associated with prominent changes in power in high gamma and low gamma frequency ranges that were either absent or attenuated when cues were missed. Both the nAChR antagonist mecamylamine and the mAChR (M1) antagonist telenzepine reduced power in the high gamma component of the detected cue-evoked LFP to levels seen when cues were missed. This high gamma synchrony was present only in the first $300 \mathrm{~ms}$ of cue presentation, before phasic ACh levels peaked and before the onset of the reward-retrieval response. Thus, nAChR and $\mathrm{mAChR}$ modulation of high gamma synchrony occurs in the earliest phases of the cue-detection process and is most likely related to cue-triggered (re)orienting that precedes the actual decision-making process. Mecamylamine did not attenuate the later emergence of sustained low gamma power. However, telenzepine abolished the sustained low gamma activity evoked by the cue on detected trials. These findings are consistent with a cholinergic and specifically muscarinic basis for the sustained low gamma oscillations observed on detected trials. Regarding the precession of events that constitute cue detection, the emergence of low gamma oscillations began $500 \mathrm{~ms}$ after cue and coincided with the postorientation decision to use the information provided by the cue.

Previous studies have noted that during cognitive performance, prefrontal gamma can be modulated by the ongoing theta rhythm (Axmacher et al., 2010; Staudigl and Hanslmayr, 2013; Kaplan et al., 2014). We also found that the amplitude of low gamma synchrony was strongly modulated by the phase of the cue-evoked theta only when cues were detected. Interestingly, cross-frequency gamma coupling to the theta phase was both frequency and time specific, was evident during the late phase of the cue detection process dominated by low gamma oscillations $(500-3000 \mathrm{~ms})$, and was not present during the early phase of cue detection, in which high gamma was most prevalent. Importantly, the increase in low gamma oscillations and the thetagamma cross-frequency coupling were sustained for several seconds following the onset of a detected cue. This temporal profile was strikingly similar to that of cue-evoked ACh release measured in this as well as previous studies (Parikh et al., 2007; Howe et al., 2013). Moreover, this theta-gamma coordination was blocked by both $\mathrm{nAChR}$ and $\mathrm{mAChR}$ receptor antagonism, indicating that activation of both receptor subtypes, which contribute to both the early and late phases of cue detection, respectively, is necessary.

In the current studies, we applied a technique for the detection of presynaptic ACh release on a subsecond time scale (see Materials and Methods; Gritton et al., 2016). Unfortunately, techniques that allow for sampling ACh release or selectively inhibiting ACh signaling, at nAChRs/mAChRs, with the same high temporal resolution typical for measurements of the local field potential do not yet exist. Thus, it is not surprising that changes in the LFP were detectable before observable changes in ACh release measured with amperometry. However, it is important to reiterate that the rapid detection-evoked increases in high gamma synchrony, as well as seconds-long increases in low gamma synchrony and theta-gamma coupling, were sensitive to cholinergic receptor antagonism. Together, these findings sup- 
port that early and late changes in the LFP during cue detection depend on ACh release, which may in turn impart a shift toward cross-frequency coordination in prefrontal circuitry and a transition from stimulus-evoked orientation to response generation.

Theta oscillations are thought to underlie the coordination of motor and sensory processing during task performance (Bland and Oddie, 2001; Cruikshank et al., 2012). In the present study, theta oscillations, like high gamma oscillations, were elevated during the early phase of cue presentation and therefore may also be tied to the visual orienting response toward the stimulus (Delorme et al., 2007). The emergence of PFC theta associated with cue onset was not significantly disrupted by either cholinergic antagonist, suggesting a distal generator for this rhythm and/or a lack of cholinergic receptor dependence at the level of the PFC. It is interesting to speculate on the origin of this rhythm and its particular role within the cue-detection circuit. Neurons of the basal forebrain fire at theta frequencies during wakefulness and rapid eye movement sleep, and inactivation of these cells reduces theta power (Manns et al., 2000a,b, 2003; Lee et al., 2005; Brandon et al., 2011; Koenig et al., 2011). Previous work has demonstrated that the synchronous activity of GABAergic projections of the basal forebrain can promote cortical theta (Lin et al., 2006). Thus, it is possible that this population of noncholinergic neurons in the basal forebrain contribute to the theta frequency component of the cue-evoked oscillation in the PFC. This possibility is particularly intriguing as it suggests that two populations of cells in the basal forebrain may preferentially contribute to the emergence of different oscillatory signals within PFC, each subserving different interrelated cognitive processes. Because these neurons can influence one another locally (Yang et al., 2014; Xu et al., 2015; Zant et al., 2016), the basal forebrain may have a remarkably strong ability to contribute to cross-frequency coupling in cortical terminal fields by coordinating postsynaptic interactions through connections that exist at their origin.

The results presented here form the basis for temporally mapping phasic ACh release events, which mediate cue detection, onto changes in the neural rhythms associated with the same cognitive process. Our data support a model in which stimulus information imported into prefrontal circuitry is shaped by cholinergic neurotransmission, which coordinates the LFP and modulates the efficacy of cue detection as well as related shifts in attentional state (Howe et al., 2013). Initially, cholinergic signaling amplifies the representation of the cue, presumably through presynaptic $\alpha 4 \beta 2 \mathrm{nAChRs} \mathrm{localized} \mathrm{on} \mathrm{thalamic} \mathrm{inputs} \mathrm{(Parikh}$ et al., 2008; Parikh et al., 2010) as well as M1 mAChRs, and thereby elevates the cue-triggered orienting response. High gamma oscillations are increased when such orienting occurs, and the cognitive operations that support cue detection may rely on this initial high-frequency rhythm to relay information about an environmental cue into the prefrontal network that initiates subsequent behavior. Muscarinic (M1) receptors coordinate the transition to low gamma synchrony, which coincides with the mobilization of networks involved in cue-based decision making that guide response generation. Low-frequency theta oscillations coincided with cue presentation on all trials regardless of whether animals used the stimulus to change ongoing behavior. The emergence of this low-frequency, "bottom-up" representation of a sensory cue did not depend on local cholinergic neurotransmission. In contrast, the coupling of these low-frequency oscillations with gamma depended on cholinergic activity. The coupling of theta with gamma could reflect the integration of the multiple phases of the cue-detection cascade: sensory input-based cuetriggered orienting coded by theta and high gamma emergence and the decision to use the information provided by the cue to guide behavior corresponding with the transition to sustained low gamma synchrony. ACh release in the PFC may then facilitate cue detection by enhancing theta-gamma coupling and thus orchestrate the multiple phases of stimulus processing.

Deficits in prefrontal cortical function associated with disorders such as schizophrenia (Uhlhaas et al., 2008; Uhlhaas and Singer, 2015) and drug addiction (Paolone et al., 2013; MoreinZamir et al., 2015; Vaquero et al., 2016) may include disruptions in both cholinergic signaling and the coordination of networks through synchronous activity. Thus, it is important to be cognizant of the complexities of cholinergic signaling, particularly the deterministic role of phasic ACh release and the impact such release events have on prefrontal circuitry. The present data reveal the highly orchestrated temporal dynamics of this relationship and highlight the necessity of an approach for developing putative pharmacological treatments for cognitive disorders that includes a full characterization of drug effects from the level of neurotransmitter release to synchronization of local networks.

\section{References}

Arnold HM, Burk JA, Hodgson EM, Sarter M, Bruno JP (2002) Differential cortical acetylcholine release in rats performing a sustained attention task versus behavioral control tasks that do not explicitly tax attention. Neuroscience 114:451-460. CrossRef Medline

Axmacher N, Henseler MM, Jensen O, Weinreich I, Elger CE, Fell J (2010) Cross-frequency coupling supports multi-item working memory in the human hippocampus. Proc Natl Acad Sci USA 107:3228-3233. CrossRef Medline

Bichot NP, Rossi AF, Desimone R (2005) Parallel and serial neural mechanisms for visual search in macaque area V4. Science 308:529-534. CrossRef Medline

Bland BH, Oddie SD (2001) Theta band oscillation and synchrony in the hippocampal formation and associated structures: the case for its role in sensorimotor integration. Behav Brain Res 127:119-136. CrossRef Medline

Bokil H, Andrews P, Kulkarni JE, Mehta S, Mitra PP (2010) Chronux: a platform for analyzing neural signals. J Neurosci Methods 192:146-151. CrossRef Medline

Brandon MP, Bogaard AR, Libby CP, Connerney MA, Gupta K, Hasselmo ME (2011) Reduction of theta rhythm dissociates grid cell spatial periodicity from directional tuning. Science 332:595-599. CrossRef Medline

Buschman TJ, Miller EK (2007) Top-down versus bottom-up control of attention in the prefrontal and posterior parietal cortices. Science 315: 1860-1862. CrossRef Medline

Canavier CC (2015) Phase re-setting as a tool of information transmission. Curr Opin Neurobiol 31:206-213. CrossRef Medline

Canolty RT, Knight RT (2010) The functional role of cross-frequency coupling. Trends Cogn Sci 14:506-515. CrossRef Medline

Caplan JB, Madsen JR, Schulze-Bonhage A, Aschenbrenner-Scheibe R, Newman EL, Kahana MJ (2003) Human theta oscillations related to sensorimotor integration and spatial learning. J Neurosci 23:4726-4736. Medline

Cohen MX (2008) Assessing transient cross-frequency coupling in EEG data. J Neurosci Methods 168:494-499. CrossRef Medline

Cohen MX (2014) Analyzing neural time series data: theory and practice. Cambridge, MA: The MIT Press.

Cohen MX, Elger CE, Fell J (2009) Oscillatory activity and phase-amplitude coupling in the human medial frontal cortex during decision making. J Cogn Neurosci 21:390-402. CrossRef Medline

Cruikshank LC, Singhal A, Hueppelsheuser M, Caplan JB (2012) Theta oscillations reflect a putative neural mechanism for human sensorimotor integration. J Neurophysiol 107:65-77. CrossRef Medline

Delorme A, Makeig S (2004) EEGLAB: an open source toolbox for analysis of single-trial EEG dynamics including independent component analysis. J Neurosci Methods 134:9-21. CrossRef Medline

Delorme A, Westerfield M, Makeig S (2007) Medial prefrontal theta bursts precede rapid motor responses during visual selective attention. J Neurosci 27:11949-11959. CrossRef Medline 
Disney AA, Aoki C (2008) Muscarinic acetylcholine receptors in macaque $\mathrm{V} 1$ are most frequently expressed by parvalbumin-immunoreactive neurons. J Comp Neurol 507:1748-1762. CrossRef Medline

Engel AK, Fries P, Singer W (2001) Dynamic predictions: oscillations and synchrony in top-down processing. Nat Rev Neurosci 2:704-716. CrossRef Medline

Faulkner HJ, Traub RD, Whittington MA (1998) Disruption of synchronous gamma oscillations in the rat hippocampal slice: a common mechanism of anaesthetic drug action. Br J Pharmacol 125:483-492. CrossRef Medline

Faulkner HJ, Traub RD, Whittington MA (1999) Anaesthetic/amnesic agents disrupt beta frequency oscillations associated with potentiation of excitatory synaptic potentials in the rat hippocampal slice. Br J Pharmacol 128:1813-1825. CrossRef Medline

Fries P, Reynolds JH, Rorie AE, Desimone R (2001) Modulation of oscillatory neuronal synchronization by selective visual attention. Science 291: 1560-1563. CrossRef Medline

Galvan M, Boer R, Schudt C (1989) Interaction of telenzepine with muscarinic receptors in mammalian sympathetic ganglia. Eur J Pharmacol 167: 1-10. CrossRef Medline

Gregoriou GG, Gotts SJ, Zhou H, Desimone R (2009) High-frequency, long-range coupling between prefrontal and visual cortex during attention. Science 324:1207-1210. CrossRef Medline

Gritton HJ, Howe WM, Mallory CS, Hetrick VL, Berke JD, Sarter M (2016) Cortical cholinergic signaling controls the detection of cues. Proc Natl Acad Sci U S A 113:E1089-E1097. Medline

Herremans AH, Hijzen TH, Welborn PF, Olivier B, Slangen JL (1996) Effects of infusion of cholinergic drugs into the prefrontal cortex area on delayed matching to position performance in the rat. Brain Res 711:102111. CrossRef Medline

Herrero JL, Roberts MJ, Delicato LS, Gieselmann MA, Dayan P, Thiele A (2008) Acetylcholine contributes through muscarinic receptors to attentional modulation in V1. Nature 454:1110-1114. CrossRef Medline

Howe WM, Berry AS, Francois J, Gilmour G, Carp JM, Tricklebank M, Lustig C, Sarter M (2013) Prefrontal cholinergic mechanisms instigating shifts from monitoring for cues to cue-guided performance: converging electrochemical and fMRI evidence from rats and humans. J Neurosci 33: 8742-8752. CrossRef Medline

Hyman JM, Zilli EA, Paley AM, Hasselmo ME (2005) Medial prefrontal cortex cells show dynamic modulation with the hippocampal theta rhythm dependent on behavior. Hippocampus 15:739-749. CrossRef Medline

Jones MW, Wilson MA (2005) Theta rhythms coordinate hippocampalprefrontal interactions in a spatial memory task. PLoS Biol 3:e402. CrossRef Medline

Jung TP, Makeig S, Westerfield M, Townsend J, Courchesne E, Sejnowski TJ (2001) Analysis and visualization of single-trial event-related potentials. Hum Brain Mapp 14:166-185. CrossRef Medline

Kaplan R, Bush D, Bonnefond M, Bandettini PA, Barnes GR, Doeller CF, Burgess N (2014) Medial prefrontal theta phase coupling during spatial memory retrieval. Hippocampus 24:656-665. CrossRef Medline

Koenig J, Linder AN, Leutgeb JK, Leutgeb S (2011) The spatial periodicity of grid cells is not sustained during reduced theta oscillations. Science 332: 592-595. CrossRef Medline

Kozak R, Bruno JP, Sarter M (2006) Augmented prefrontal acetylcholine release during challenged attentional performance. Cereb Cortex 16:917. Medline

Lakatos P, Shah AS, Knuth KH, Ulbert I, Karmos G, Schroeder CE (2005) An oscillatory hierarchy controlling neuronal excitability and stimulus processing in the auditory cortex. J Neurophysiol 94:1904-1911. CrossRef Medline

Laubach M, Caetano MS, Narayanan NS (2015) Mistakes were made: neural mechanisms for the adaptive control of action initiation by the medial prefrontal cortex. J Physiol Paris 109:104-117. CrossRef Medline

Lee MG, Hassani OK, Alonso A, Jones BE (2005) Cholinergic basal forebrain neurons burst with theta during waking and paradoxical sleep. J Neurosci 25:4365-4369. CrossRef Medline

Leventhal DK, Gage GJ, Schmidt R, Pettibone JR, Case AC, Berke JD (2012) Basal ganglia beta oscillations accompany cue utilization. Neuron 73:523536. CrossRef Medline

Lin SC, Gervasoni D, Nicolelis MA (2006) Fast modulation of prefrontal cortex activity by basal forebrain noncholinergic neuronal ensembles. J Neurophysiol 96:3209-3219. CrossRef Medline

Manns ID, Alonso A, Jones BE (2000a) Discharge properties of juxtacellularly labeled and immunohistochemically identified cholinergic basal forebrain neurons recorded in association with the electroencephalogram in anesthetized rats. J Neurosci 20:1505-1518. Medline

Manns ID, Alonso A, Jones BE (2000b) Discharge profiles of juxtacellularly labeled and immunohistochemically identified GABAergic basal forebrain neurons recorded in association with the electroencephalogram in anesthetized rats. J Neurosci 20:9252-9263. Medline

Manns ID, Alonso A, Jones BE (2003) Rhythmically discharging basal forebrain units comprise cholinergic, GABAergic, and putative glutamatergic cells. J Neurophysiol 89:1057-1066. Medline

McGaughy J, Kaiser T, Sarter M (1996) Behavioral vigilance following infusions of 192 IgG-saporin into the basal forebrain: selectivity of the behavioral impairment and relation to cortical AChE-positive fiber density. Behav Neurosci 110:247-265. CrossRef Medline

Morein-Zamir S, Simon Jones P, Bullmore ET, Robbins TW, Ersche KD (2015) Take it or leave it: prefrontal control in recreational cocaine users. Transl Psychiatry 5:e582. CrossRef Medline

Narayanan NS, Cavanagh JF, Frank MJ, Laubach M (2013) Common medial frontal mechanisms of adaptive control in humans and rodents. Nat Neurosci 16:1888-1895. CrossRef Medline

Nelson CL, Sarter M, Bruno JP (2005) Prefrontal cortical modulation of acetylcholine release in posterior parietal cortex. Neuroscience 132:347359. CrossRef Medline

Newman EL, Gillet SN, Climer JR, Hasselmo ME (2013) Cholinergic blockade reduces theta-gamma phase amplitude coupling and speed modulation of theta frequency consistent with behavioral effects on encoding. J Neurosci 33:19635-19646. CrossRef Medline

Newman LA, Mair RG (2007) Cholinergic modulation of visuospatial responding in central thalamus. Eur J Neurosci 26:3543-3552. CrossRef Medline

Nguyen DP, Lin SC (2014) A frontal cortex event-related potential driven by the basal forebrain. Elife 3:e02148. Medline

Noronha-Blob L, Canning B, Costello D, Kinnier WJ (1988) Selective agents for muscarinic receptors linked to phosphoinositide breakdown. Eur J Pharmacol 154:161-167. CrossRef Medline

Paolone G, Angelakos CC, Meyer PJ, Robinson TE, Sarter M (2013) Cholinergic control over attention in rats prone to attribute incentive salience to reward cues. J Neurosci 33:8321-8335. CrossRef Medline

Parikh V, Sarter M (2006) Cortical choline transporter function measured in vivo using choline-sensitive microelectrodes: clearance of endogenous and exogenous choline and effects of removal of cholinergic terminals. J Neurochem 97:488-503. CrossRef Medline

Parikh V, Pomerleau F, Huettl P, Gerhardt GA, Sarter M, Bruno JP (2004) Rapid assessment of in vivo cholinergic transmission by amperometric detection of changes in extracellular choline levels. Eur J Neurosci 20: 1545-1554. CrossRef Medline

Parikh V, Kozak R, Martinez V, Sarter M (2007) Prefrontal acetylcholine release controls cue detection on multiple timescales. Neuron 56:141154. CrossRef Medline

Parikh V, Man K, Decker MW, Sarter M (2008) Glutamatergic contributions to nicotinic acetylcholine receptor agonist-evoked cholinergic transients in the prefrontal cortex. J Neurosci 28:3769-3780. CrossRef Medline

Parikh V, Ji J, Decker MW, Sarter M (2010) Prefrontal beta2 subunitcontaining and alpha7 nicotinic acetylcholine receptors differentially control glutamatergic and cholinergic signaling. J Neurosci 30:35183530. CrossRef Medline

Posner MI, Snyder CR, Davidson BJ (1980) Attention and the detection of signals. J Exp Psychol 109:160-174. CrossRef Medline

Raghavachari S, Kahana MJ, Rizzuto DS, Caplan JB, Kirschen MP, Bourgeois B, Madsen JR, Lisman JE (2001) Gating of human theta oscillations by a working memory task. J Neurosci 21:3175-3183. Medline

Rodriguez R, Kallenbach U, Singer W, Munk MH (2004) Short- and longterm effects of cholinergic modulation on gamma oscillations and response synchronization in the visual cortex. J Neurosci 24:10369-10378. CrossRef Medline

Saleh M, Reimer J, Penn R, Ojakangas CL, Hatsopoulos NG (2010) Fast and slow oscillations in human primary motor cortex predict oncoming behaviorally relevant cues. Neuron 65:461-471. CrossRef Medline

Sarter M, Lustig C, Berry AS, Gritton H, Howe WM, Parikh V (2016) What 
do phasic cholinergic signals do? Neurobiol Learn Mem 130:135-141. CrossRef Medline

Staudigl T, Hanslmayr S (2013) Theta oscillations at encoding mediate the context-dependent nature of human episodic memory. Curr Biol 23: 1101-1106. CrossRef Medline

St Peters M, Demeter E, Lustig C, Bruno JP, Sarter M (2011) Enhanced control of attention by stimulating mesolimbic-corticopetal cholinergic circuitry. J Neurosci 31:9760-9771. CrossRef Medline

Tort AB, Kramer MA, Thorn C, Gibson DJ, Kubota Y, Graybiel AM, Kopell NJ (2008) Dynamic cross-frequency couplings of local field potential oscillations in rat striatum and hippocampus during performance of a T-maze task. Proc Natl Acad Sci U S A 105:20517-20522. CrossRef Medline

Tort AB, Komorowski RW, Manns JR, Kopell NJ, Eichenbaum H (2009) Theta-gamma coupling increases during the learning of item-context associations. Proc Natl Acad Sci U S A 106:20942-20947. CrossRef Medline

Tort AB, Komorowski R, Eichenbaum H, Kopell N (2010) Measuring phase-amplitude coupling between neuronal oscillations of different frequencies. J Neurophysiol 104:1195-1210. CrossRef Medline

Uhlhaas PJ, Singer W (2015) Oscillations and neuronal dynamics in schizophrenia: the search for basic symptoms and translational opportunities. Biol psychiatry 77:1001-1009. CrossRef Medline

Uhlhaas PJ, Haenschel C, Nikolić D, Singer W (2008) The role of oscillations and synchrony in cortical networks and their putative relevance for the pathophysiology of schizophrenia. Schizophr Bull 34:927-943. CrossRef Medline

Vaquero L, Camara E, Sampedro F, Perez de Los Cobos J, Batlle F, Fabregas JM, Sales JA, Cervantes M, Ferrer X, Lazcano G, Rodriguez-Fornells A, Riba J (2016) Cocaine addiction is associated with abnormal prefrontal function, increased striatal connectivity and sensitivity to monetary incentives, and decreased connectivity outside the human reward circuit.
Addict Biol. Advance online publication. Retrieved February 27, 2017. doi:10.1111/abd.12356. Medline

Verbeke G, Molenberghs G (2009) Linear mixed models for longitudinal data. New York: Springer.

von Stein A, Sarnthein J (2000) Different frequencies for different scales of cortical integration: from local gamma to long range alpha/theta synchronization. Int J Psychophysiol 38:301-313. CrossRef Medline

Wang L, Saalmann YB, Pinsk MA, Arcaro MJ, Kastner S (2012) Electrophysiological low-frequency coherence and cross-frequency coupling contribute to BOLD connectivity. Neuron 76:1010-1020. CrossRef Medline

Womelsdorf T, Fries P (2006) Neuronal coherence during selective attentional processing and sensory-motor integration. J Physiol Paris 100:182193. CrossRef Medline

Womelsdorf T, Fries P (2007) The role of neuronal synchronization in selective attention. Curr Opin Neurobiol 17:154-160. CrossRef Medline

Woodman GF (2010) A brief introduction to the use of event-related potentials in studies of perception and attention. Atten Percep Psychophys 72:2031-2046. CrossRef

Xu M, Chung S, Zhang S, Zhong P, Ma C, Chang WC, Weissbourd B, Sakai N, Luo L, Nishino S, Dan Y (2015) Basal forebrain circuit for sleep-wake control. Nat Neurosci 18:1641-1647. CrossRef Medline

Yang C, McKenna JT, Zant JC, Winston S, Basheer R, Brown RE (2014) Cholinergic neurons excite cortically projecting basal forebrain GABAergic neurons. J Neurosci 34:2832-2844. CrossRef Medline

Zant JC, Kim T, Prokai L, Szarka S, McNally J, McKenna JT, Shukla C, Yang C, Kalinchuk AV, McCarley RW, Brown RE, Basheer R (2016) Cholinergic neurons in the basal forebrain promote wakefulness by actions on neighboring noncholinergic neurons: an opto-dialysis study. J Neurosci 36:2057-2067. CrossRef Medline 